\title{
Posttraumatic stress disorder and posttraumatic stress disorder-like symptoms and mild traumatic brain injury
}

\author{
Jan E. Kennedy, PhD; ${ }^{*}$ Michael S. Jaffee, MD; ${ }^{1}$ Gregory A. Leskin, PhD; ${ }^{2}$ James W. Stokes, MD; $^{1}$ Felix $O$. \\ Leal, MA; ${ }^{1}$ Pamela J. Fitzpatrick, PhD $^{1}$ \\ ${ }_{1}^{1}$ Defense and Veterans Brain Injury Center, Department of Neurology, Wilford Hall Air Force Medical Center, Lackland \\ Air Force Base, TX; ${ }^{2}$ National Center for Posttraumatic Stress Disorder, Education and Clinical Laboratory, Department \\ of Veterans Affairs Palo Alto Health Care System, Palo Alto, CA; ${ }^{3}$ Psychiatry Service, Department of Behavioral \\ Medicine, Brooke Army Medical Center, Fort Sam Houston, TX
}

\begin{abstract}
In this article, we review the literature on posttraumatic stress disorder (PTSD) and PTSD-like symptoms that can occur along with mild traumatic brain injury (TBI) and concussion, with specific reference to concussive injuries in the military. We address four major areas: (1) clinical aspects of TBI and PTSD, including diagnostic criteria, incidence, predictive factors, and course; (2) biological interface between PTSD and TBI; (3) comorbidity between PTSD and other mental disorders that can occur after mild TBI; and (4) current treatments for PTSD, with specific considerations related to treatment for patients with mild TBI or concussive injuries.
\end{abstract}

Key words: biological factors, blast concussion, clinical course, comorbidity, concussion, incidence, mild traumatic brain injury, rehabilitation, posttraumatic stress disorder, traumatic brain injury, treatment.

\section{INTRODUCTION}

The role of subtle persistent brain injury in the development and course of acute stress disorder (ASD) and posttraumatic stress disorder (PTSD) has been controversial, although many clinicians and medical authorities, as well as the public and media, assume that a relationship exists [1]. The military conflicts Operation Enduring Freedom (OEF) and Operation Iraqi Freedom (OIF) have brought to the forefront the issue of the relationship of concussion and blunt head trauma to combat stress reactions and combat- induced PTSD. As of June 25, 2007, over 26,000 U.S. service members have been wounded in action in OIF (www.defenselink.mil/news/casualty.pdf). Slightly more than half of combat injuries incurred early in OIF was from explosive blasts [2]. In addition to blasts, service members are at risk for head and bodily injuries due to projectiles

\footnotetext{
Abbreviations: $\mathrm{ACTH}=$ adrenocorticotropic hormone, $\mathrm{ASD}=$ acute stress disorder, $\mathrm{CBT}=$ cognitive behavioral therapy, $\mathrm{CPG}=$ Clinical Practice Guidelines, CRF = corticotrophin-releasing factor, DOD = Department of Defense, DSM = Diagnostic and Statistical Manual, DSM-III = DSM-Third Edition, DSM-III-R = DSMIII-Revised, DSM-IV-TR = DSM-Fourth Edition-Text Revised, EMDR = eye movement desensitization and reprocessing, fMRI = functional magnetic resonance imaging, GABA = gamma-aminobutyric acid, HPA = hypothalamicpituitary-adrenal, $\mathrm{LOC}=$ loss of consciousness, $\mathrm{MVA}=$ motor vehicle accident, NCS $=$ National Comorbidity Survey, OEF = Operation Enduring Freedom, OIF = Operation Iraqi Freedom, $\mathrm{PET}=$ positron emission tomography, $\mathrm{PTA}=$ posttraumatic amnesia, PTSD = posttraumatic stress disorder, SSRI = selective serotonergic reuptake inhibitor, $\mathrm{TBI}=$ traumatic brain injury, VA = Department of Veterans Affairs.

*Address all correspondence to Jan E. Kennedy, PhD; Defense and Veterans Brain Injury Center, 59MHS/SGON, 2200 Bergquist Dr, Suite 1, Lackland AFB, TX 78236-9908; 210-292-7230; fax: 210-292-2029.

Email: janlizkennedy@yahoo.com

DOI: 10.1682/JRRD.2006.12.0166
} 
(bullets, fragments), transportation accidents, and other environmental and combat hazards. Between January 2003 and February 2007, 29 percent of the patients evacuated from the combat theater to Walter Reed Army Medical Center in Washington, DC, had evidence of a traumatic brain injury (TBI).

To estimate the frequency of concussion among combat troops who do not require medical treatment and evacuation is difficult. Many may be only briefly stunned or knocked unconscious by a blast or blow. However, even mild concussion, if recurrent, can cumulatively affect brain functions. Questions assessing TBI among all homecoming service members have been proposed to be included on the Post Deployment Health Assessment (a Department of Defense [DOD] form DD2796 to be completed when a service member returns from duty). Improved data collection at unit level and higher echelons of field medical care is currently being implemented.

In combat, experiences of fear, horror, and helplessness are ubiquitous. Does the occurrence of concussion increase the severity or likeliness of PTSD? Program evaluation data from U.S. marines surveyed following OIF indicate that combat troops reporting exposure to blasts had significantly higher levels of PTSD. In studies on the relationship between PTSD and injury of Vietnam veterans, findings showed two- to threefold higher rates of PTSD among this population than those who returned unharmed [3-4]. Furthermore, recent studies show that physical injury due to combat is a major risk factor for PTSD [5]. Thus PTSD is more likely among combat veterans who are injured. A review of the literature shows an increased rate of PTSD after TBI, with data from six studies yielding an estimated relative risk of 1.8 of those who developed PTSD over a maximum period of 7.5 years [6].

In this article, we review the current literature on PTSD and PTSD-like symptoms among individuals with mild TBI or concussion. We discuss four major areas. In the first area, we present general incidence studies of PTSD and effects of mild TBI on rates of PTSD symptoms, followed by a review of the literature on predictive factors and course of development of PTSD after TBI. We also present symptoms and symptom overlap between TBI and PTSD. Second, we review the neurobiology of PTSD and TBI. In the third area, we discuss the common psychiatric

*Defense and Veterans Brain Injury Center. Operation Iraqi Freedom (OIF)/Operation Enduring Freedom (OEF) Fact Sheet: February 2007. comorbidities associated with PTSD. In the fourth and final area, we focus on the general treatment and outcome of PTSD in the context of TBI.

\section{CLINICAL ASPECTS}

\section{Traumatic Brain Injury}

\section{Mechanisms and Criteria}

TBI may arise from physical damage by external blunt or penetrating trauma to the head, skull, dura, or brain or from acceleration-deceleration movement such as whiplash or coup-contrecoup, resulting in tearing or shearing of nerve fibers and bruising or contusion of the brain against opposite sides of the skull. Scraping of the brain across the rough bony base of the skull can cause contusion and can also affect the olfactory, oculomotor, optic, and acoustic nerves, leading to anosmia (total loss of the sense of smell, reduction of taste), double and/or blurred vision, and dizziness and/or vertigo. These symptoms usually remit after days and weeks as the damaged axons in those nerves recover or grow back to reinnervate the sensory receptors or muscles.

With regard to blast-related concussions, the consequences of primary blast on the brain are controversial [7]. However, the mechanism and sequelae of brain overpressurization from blast are similar to those in the fluid percussion animal model of mild TBI [8]. Exposure to blast overpressurization induces ultrastructural and biochemical alterations and associated cognitive deficits in rats [9]. Other effects of blast on the brain are the same as those involved in brain injuries incurred in other contexts. These blast effects include being struck in the head by debris and shrapnel (secondary effect) and being struck in the head when thrown into a stationary object (tertiary effect) [10]. Quaternary effects unique to blast explosion include burns and injury due to inhalation of toxic fumes, smoke, and/or dust [11].

TBI can be categorized by severity in three levels: mild, moderate, and severe. Various clinical criteria have been used to define mild TBI, with no definite consensus [12]. However, a generally accepted definition proposed by the American Congress of Rehabilitation Medicine includes (1) associated diminished or altered state of or loss of consciousness (LOC), i.e., interruption of awareness of oneself and surroundings for less than 30 minutes; (2) posttraumatic amnesia (PTA), i.e., memory disruption 
following injury (not able to store or retrieve new information) for less than 24 hours, and (3) a Glasgow Coma Scale score of 13 or greater quantifying level of consciousness [13].

\section{Symptoms}

With most TBIs, a set of postconcussive symptoms occur immediately after brain injury and can include cognitive deficits in memory, attention, and concentration; physical or somatic complaints of fatigue, disordered sleep, dizziness, and headache; and affective complaints of irritability, anxiety, and depression. In evaluating the symptoms associated with TBI, clinicians should account for multiple factors related to the characteristics of the individual injured, severity of the injury, and the time interval from injury to evaluation that can influence the level of functional and cognitive performance [14]. Mild TBI can cause cognitive deficits not only in speed of information processing, attention, and memory in the immediate postinjury period but also in motor skills and new problem-solving and general intellectual skills [15].

Fortunately, good recovery of postconcussive deficits can be expected over a time ranging from 4 to 12 weeks for the majority of patients with mild TBI cases. However, some patients may recover much more slowly, with symptoms lingering for several more months [16] or even years [17]. In terms of the emotional sequelae of TBI, Rao and Lyketsos state the most common post-TBI anxiety symptoms include "free-floating anxiety, fearfulness, intense worry, generalized uneasiness, social withdrawal, interpersonal sensitivity and anxiety dreams" [18]. These symptoms are also similar to characteristic PTSD symptoms and therefore can be a problematic overlap in considering PTSD incidence rates in those persons with mild TBI.

\section{Posttraumatic Stress Disorder}

\section{Criteria and Symptoms}

As defined in the Diagnostic and Statistical Manual (DSM)-Fourth Edition-Text Revised (DSM-IV-TR), PTSD is an anxiety disorder comprising four major criteria:

1. Exposure to or witnessing an event that is threatening to one's well-being and responding with intense fear, helplessness, or horror.

2. Symptoms of reexperiencing, such as recurrent and intrusive memories, nightmares, a sense of reliving the trauma, or psychological and physiological distress when reminded of aspects of the trauma.
3. Avoidance of thoughts, feelings, or reminders of the trauma, and the inability to recall parts of the trauma, withdrawal, and emotional numbing.

4. Arousal increases, as manifested in sleep disturbance, irritability, difficulty concentrating, hypervigilance, or exaggerated startle response.

These symptoms must cause marked impairment in functioning and persist for at least 1 month after the trauma [19]. PTSD also has accompanying cognitive effects that include impaired concentration and decision making, memory impairment and confusion; behavioral symptoms of increased relational conflict resulting in social withdrawal, alienation, reduced relational intimacy and impaired work and school performance; and somatic complaints of exhaustion, insomnia, headaches, startle response, hyperarousal, and cardiovascular, gastrointestinal, and musculoskeletal disorders [20].

Symptoms of reexperiencing the extremely traumatic event through nightmares and intrusive thoughts are a main feature of PTSD and are significant in the controversy over the coexistence of PTSD and TBI. One important issue is whether PTSD can develop after brain injury with associated LOC, PTA, or cognitive impairment resulting in no recollection of the actual traumatic event [13]. Growing evidence and acceptance have shown that PTSD can occur after TBI, but the reported prevalence rates vary widely by study from 0 to 56 percent [21-23].

In addition to intense and free-floating anxiety and distress that PTSD causes, a variety of cognitive problems manifest, including impaired learning and forgetfulness, attention and concentration difficulties, slower processing speed, and a sense of being overwhelmed with once simple tasks, which may be mistaken for signs of TBI. Conversely, changes in personality such as impulsiveness, reduced insight, rigid thinking, and reduced motivation caused by TBI may also be misdiagnosed as PTSD. Differential diagnosis can be further complicated by the number of overlapping symptoms for PTSD and chronic postconcussion syndrome, including noise sensitivity, fatigue, anxiety, insomnia, poor concentration, poor memory, irritability/anger, and depression [24-26]. Hovland and Raskin conducted a study that suggests PTSD can exacerbate cognitive symptoms in mild TBI [27]. Hence, differential diagnosis of PTSD requires understanding the etiology of the different symptoms commonly seen after TBI. Obtaining accurate information to account for the presenting neurological and psychological factors may suggest specific underlying mechanisms that can help in 
early detection, diagnosis, and treatment. These efforts can ultimately improve outcomes from the disabling manifestations of chronic postconcussive syndrome and PTSD that interfere with recovery and adaptation to life after brain injury.

\section{Incidences}

Estimates of the lifetime prevalence of PTSD are 7 to 9 percent in community samples in the United States [2831]. PTSD incidence rates range from 3 to 30 percent in groups exposed to specific traumatic incidents such as war, torture, or rape [32]. Combat exposure is one of several factors that have been identified as being associated with increased risk for PTSD. An analysis of the lifetime prevalence of PTSD in male veterans who served in Southeast Asia during the Vietnam war era (1965-1975) shows a 30 percent incidence rate compared with a 5 percent incidence rate in the general population of men [33]. An investigation focused on PTSD symptom rates, as opposed to PTSD diagnosis, found that 69 percent of a large sample of over 4,000 Army personnel exposed to combat in the Persian Gulf war reported at least one reexperiencing symptom, 37 percent reported at least three avoidance symptoms, and 46 percent reported at least two arousal symptoms at 9 to 10 months postwar [34]. In addition to the high rate of PTSD exposure to combat exposure, risk for PTSD is also higher when a physical injury has been received [5]. For example, two to three times higher rates of PTSD have been found among injured Vietnam veterans compared with noninjured veterans [3-4]. Of the soldiers injured in combat in Israel from 1998 to 2000, 17.0 percent developed PTSD compared with 2.5 percent of noninjured demographically similar soldiers who were exposed to the same combat situations [5]. In a nonmilitary environment, exposure to assaultive crime or witnessed homicide has been shown to increase PTSD rates (26\% vs $9 \%$ ) compared with other types of trauma in a large sample of U.S. adult women [35].

Estimates of the prevalence rates of PTSD following TBI vary dramatically, from 0 to 50 percent, depending on the study [36]. One review cites a 20 to 40 percent incidence of PTSD after head injury [37]. A recent study of 120 Israelis with mild TBI, mostly from motor vehicle accidents (MVAs), reported a 14 percent incidence rate of DSM-IV-diagnosed PTSD 6 months after injury [38]. Another study in a U.S. sample reported a 13 percent incidence of PTSD 3 months after mild TBI among cases involving primarily MVAs and assaults or fights [39].

\section{Influence of Posttraumatic Amnesia}

The development of PTSD symptoms after TBI may depend on the presence and duration of PTA. A debate is ongoing as to whether PTSD occurs after a TBI in which amnesia for the traumatic event occurs [40]. Some reports indicate that PTSD does not develop without conscious awareness of the event [41-44]. Other findings demonstrate that PTSD can occur despite the presence of PTA [24,36-37,45-47]. A recent study reported that 27 percent of patients with TBI and no extended LOC developed PTSD, whereas only 1 of 31 who were unconscious for more than 12 hours developed the disorder, suggesting that PTSD is much less common in cases with a period of amnesia but occasionally can develop, even with protracted LOC [48].

Several mechanisms have been proposed for the expression of PTSD in the absence of memories for the traumatic event. These mechanisms include the islands of memory within the period of PTA $[25,49]$, short or incomplete amnesia [50], memories from before and/or after the actual event [48], implicit unconscious memories [51-52], and memories based on details the individual has later heard or seen about the event [53-54].

Recent studies have focused on the specific symptoms of PTSD that are most susceptible to being blocked by PTA. Since reexperiencing symptoms theoretically require prior encoding of traumatic elements, PTA might be susceptible to reducing or eliminating them. Studies have suggested that reexperiencing symptoms are often absent or reduced when conscious awareness or memory of the traumatic event does not exist $[38,44,48]$. Other evidence suggests that both reexperiencing and avoidance symptoms are reduced (but not eliminated) in patients with PTA of more than 1 hour [46]. Bryant and colleagues examined the incidence of specific symptoms within the reexperiencing cluster [52]. Intrusive reexperiencing symptoms occurred infrequently 6 months after severe TBI with amnesia, being reported by 19.2 percent of the participants in this study. In contrast, the reexperiencing symptom of emotional reactivity (becoming upset by reminders of the traumatic experience) was reported by 96.2 percent of the sample. These findings suggest that reexperiencing symptoms based on psychological and emotional conditioning are enhanced in patients after severe TBI.

In cases of mild TBI and blast concussion, little or no LOC or amnesia may occur for the time of the event. However, in combat environments, other systemic injuries and polytrauma provide confounding factors. Combat troops 
located in the combat zone are likely to be in a state of high vigilance and arousal before the TBI event and may already have experienced incidents that met Criterion A for PTSD. (In DSM-IV-TR, Criterion A is defined as the person having experienced, witnessed, or been confronted with an event or events that involved actual or threatened death or serious injury or a threat to the physical integrity of self or others and the person's response having involved fear, horror, or helplessness.) Treatment of severe burns and orthopedic injuries may invoke prolonged helplessness and horror at one's own condition, pain, and fear sufficient to meet Criterion A. Use of sedatives and analgesic medications has strong effects on level of consciousness and memory processing. Although these factors affect the incidence of PTSD, the extent to which these factors alter the development and expression of specific PTSD symptoms is speculative.

\section{Predictive Factors}

Risk factors for PTSD include pretrauma, peritrauma (at the time of the traumatic event), and posttrauma variables. Evidence suggests that different factors are involved in the development versus the maintenance of PTSD [55]. According to several studies, past psychiatric history, prior trauma, and the presence of PTSD symptoms immediately following the trauma have relatively low predictive value for later PTSD [56-58]. A meta-analysis of risk factors found only modest effects, but it suggested that peri- and posttraumatic factors such as trauma severity, lack of social support, and life stress were more strongly related to post-PTSD than pretrauma factors [59]. A separate meta-analysis concluded that peritraumatic psychological processes more strongly predict PTSD than prior factors of past trauma, psychological adjustment, and family history of psychopathology [60]. Trauma severity most significantly predicted PTSD severity, followed by posttrauma interpersonal connection, and pretrauma conduct disorder in a study of prisoners of war [61]. Severity of injury was also related to PTSD diagnosis 6 months after MVAs in another study [62]. In a community sample of survivors of severe TBI, a PTSD symptom report was not related to TBI severity, survivors' educational background, preinjury or current IQ (intelligence quotient), or memory impairment. Positive factors for PTSD symptoms included level of insight and external attributions to others of causality for the event. These results suggest that although severity of the traumatic event appears to relate to development of PTSD, severity of TBI itself could be less predictive. Since all patients in this study had severe TBI, restriction of range could also account for these negative results [63]. Predictors of early posttraumatic acute stress severity resemble the predictors of PTSD [64]. Several studies provide evidence for the predictive value of acute symptoms on subsequent PTSD. For example, a study with victims of violent crime found that a diagnosis of ASD correctly predicted subsequent PTSD for 83 percent of the group and presence of at least three reexperiencing or arousal symptoms similarly predicted PTSD [65]. Studies in MVA victims have also established a relationship between acute stress symptoms and the presence of PTSD at 1-year follow-up [66-67]. Similarly, early acute stress symptoms were related to PTSD in patients with mild TBI after MVAs [69].

Despite this evidence, a recent review of 10 studies concluded that acute biological and cognitive mechanisms better predict PTSD than a diagnosis of ASD or any constellation of acute symptoms [69]. A recent prospective study conducted on firefighter training graduates found that high levels of hostility and low levels of selfefficacy at baseline (before exposure to traumatic on-thejob events) related to PTSD symptoms 2 years later [70]. Results are consistent with those from earlier studies establishing associations between high hostility and anger, reduced self-efficacy, and PTSD and further suggest that these characteristics are factors that predict PTSD [71-77]. A recent study has also suggested that PTSD in firefighters relates to pretrauma degree of catastrophic thinking [78]. These and other studies indicate that psychological and psychosocial factors prominently affect susceptibility to PTSD [79-81].

Studies of biological risk factors suggest that PTSD is related to altered hypothalamic-pituitary-adrenal (HPA) axis function. This finding is characterized by low basal cortisol levels and enhanced negative feedback regulation. These neuroendocrine alterations have been shown to occur within hours after trauma [56,82-83]. In addition, the genetic factors that contribute to risk for PTSD have been examined. Further review of these areas is found in the "Biological Interface Between Posttraumatic Stress Disorder and Traumatic Brain Injury” section.

In summary, current literature appears to confirm a strong association of peritraumatic thoughts, feelings, and biological events to subsequent development of PTSD. Acute stress symptoms are somewhat less predictive, and remote pretrauma variables are more weakly related to PTSD. No known empirical evidence directly documents 
a change in the incidence of PTSD because of alterations of biological and psychological peritraumatic risk factors specifically associated with TBI. However, the biological and psychological risk factors for PTSD theoretically occur during traumatic events in which TBI is experienced. These factors can be exacerbated by TBI, leading to the documented increase in PTSD rates following TBI.

Sex effects on the prevalence of lifetime PTSD are well documented, with a female-to-male lifetime prevalence ratio of 2:1 [84]. The greater susceptibility of women to PTSD contrasts with their exposure to fewer traumatic events but corresponds to a greater lifetime risk of rape and sexual assault trauma. Evidence suggests that stress hormone system sensitization from early exposure to negative experiences, neuroendocrine factors, subjective interpretation of the event, and peritraumatic dissociation may influence the higher rates of PTSD in women [85]. Sex differences in PTSD have also been associated with higher rates of preexisting anxiety disorders or major depressive disorders in women and with trauma exposure in women before the age of 15 [86]. However, these associations based on the literature just cited that suggests low predictive value for such preexisting psychiatric disorders may not be causally related to the incidence of PTSD. Sex differences exist for TBI, with males more likely than females to experience TBI [87]. This finding is attributed to the fact that higher proportions of males engage in behaviors, activities, and vocations that place them at risk for TBI. Based on such situational factors, males and females in the same combat situation would be at equivalent risk for TBI.

\section{Longitudinal Course}

PTSD is often associated with a chronic course. One review article identified and examined 11 categories of potential risk factors for chronic PTSD [88]. A prospective community sample study in Germany examining the natural course of PTSD found that 52 percent of those diagnosed with PTSD at baseline remitted at follow-up 34 to 50 months later [89]. Those who did not remit were more likely to have experienced an additional traumatic event during the follow-up period and were more likely to report other comorbid anxiety and somatoform disorders. A study of PTSD in Vietnam veterans reports that PTSD symptoms developed at the time of exposure to combat trauma, with hyperarousal symptoms occurring first, followed by avoidant and then intrusive symptoms. Symptoms were found to increase rapidly over the first several years and then plateau to become chronic and unremitting [90]. Similarly, a follow-up study of patients who were injured in MVAs found that 53 percent of the patients with PTSD 1 year after the MVA continued to express PTSD 4 years postinjury [67].

PTSD is known to have high rates of comorbidity with other mental disorders. A review of this literature is included in the "Comorbidity of PTSD and Other Mental Disorders and Interface with TBI" section. The detrimental effect of comorbid disorders on recovery from PTSD has been suggested. For example, studies of PTSD in samples of patients with other anxiety disorders found low rates of remission of the PTSD (18\%) over 2.5 years of follow-up [91-92]. The high rates of comorbid conditions that occur with PTSD contribute to the chronicity of this disorder [93]. Findings of one recent study indicated that comorbid major depression predicted continuing PTSD 1 year after flood disaster, whereas in contrast with other investigations, comorbid substance abuse and somatization were not [94].

Evidence suggests that acute symptoms may be associated with later PTSD, as discussed previously. In addition, acute symptoms also appear to correlate with PTSD chronicity. A long-term follow-up study in combat veterans reported that those with acute combat stress reactions were more than six times likely to report PTSD at 1, 2, 3, and 20 years postcombat [95]. Similarly, Persian Gulf war veterans who reported PTSD symptoms immediately after the war were up to 20 times more likely to report continued symptoms 2 years postcombat [96]. Early symptoms of PTSD have been shown to predict later PTSD more than either the severity of the accident or injury [97]. Some studies have found that individuals with many avoidance symptoms at baseline have a more chronic course of PTSD [89,98]. In contrast, a longitudinal study in adult survivors of community violence found that pronounced hyperarousal at baseline predicted PTSD chronicity and lower overall symptom improvement over time [99].

The initial categorization of PTSD in DSM-III (Third Edition) [100] included the subcategory of Delayed PTSD, in which symptoms did not appear until more than 6 months after the traumatic event and even as long as several years. The validity of this diagnosis is controversial. Recent prospective studies have suggested that cases of delayed-onset PTSD exist. For example, a study identified a subset of U.S. military peacekeepers in Somalia who endorsed minimal PTSD symptoms initially but reported 
significant symptoms later [101]. Large-scale retrospective studies by the Walter Reed Army Institute of Research have shown that many more U.S. Army and marine soldiers screen positive for PTSD and other mental disorders on standard surveys administered more than 6 months after redeployment from OIF/OEF than they did immediately on homecoming [102-103]. U.S. Army policy now directs that all returnees be rescreened after 6 months. The question remains: How many of these soldiers actually developed new symptoms more than 6 months after homecoming or actually underreported significant symptoms on homecoming? Possible reasons for soldiers to initially underreport include believing that revealing symptoms could delay their rejoining their families and cast a stigmatizing shadow on their medical records and assuming that symptoms would improve spontaneously in the bliss of being safely home.

Some older veterans are diagnosed with delayed PTSD for the first time after retirement and after they suffer painful, disabling conditions of old age and the deaths of friends and spouses [104]. The authors of this study suggested that the PTSD symptoms may have been due to environmental stressors along with age-related neurodegeneration. Some of these veterans may truly have had only the normal combat and postcombat symptoms earlier in life. However, others may have struggled in silence with distressing and disruptive PTSD over many years. In either case, rehabilitation specialists should be alert to this possibility in their older veteran patients.

Combat trauma may differ from other traumatic experiences by producing more severe and/or chronic PTSD. An analysis of a subsample from the National Comorbidity Survey (NCS) found that men reporting combat as their worst trauma were more likely to have lifetime PTSD with delayed symptom onset and unremitted symptoms than men reporting other types of trauma as the worst. They were also more likely to be unemployed, fired, divorced, and physically abusive to their spouses [105]. The prevalence of PTSD in aging veterans of the Netherlands military was stable from 1992 to 1998, confirming a chronic course of PTSD in a military sample [106]. A long-term follow-up study in a large sample of Vietnam veterans reported that chronic PTSD was most strongly associated with combat exposure [107]. Discomfort in disclosing war experiences was correlated with increased risk for PTSD but not with subsequent course of the disorder. Perceived social support and community involvement were associated with increased recovery from PTSD. Another recent report of a 6-year longitudinal study of Vietnam veterans who were treated in an inpatient program for PTSD confirmed the chronicity and high mortality of this group [108]. The program's impact on the symptomatic course of illness was negligible, but the veterans' levels of violence and substance use decreased, suggesting an increase in their ability to cope with the disorder. In a study of Persian Gulf war veterans [109], two distinct groups were identified: one with low levels of PTSD and increasing symptoms over time and another with higher initial levels of symptoms and increasing symptoms over time. Characteristics of the less symptomatic group included male, white race, higher education, and less combat exposure.

Limited research has examined the longitudinal course of PTSD after TBI. One study of PTSD in children who experienced MVAs found high rates of reported PTSD symptoms at 6 and 13 weeks postinjury, but no significant differences in rates of PTSD for those with and without TBI [110]. The presence of PTSD appears to hinder recovery from TBI [111]. One unusual interaction between PTSD reexperiencing symptoms and status postTBI is a case in which the reexperienced traumatic event apparently became a perseverated response [112]. During exposure treatment, a continuous and perseverative reexperiencing of the most distressing part of the traumatic event occurred, which lasted over 7 to 10 days. The perseveration was attributed to executive impairment incurred during the head injury.

\section{BIOLOGICAL INTERFACE BETWEEN POSTTRAUMATIC STRESS DISORDER AND TRAUMATIC BRAIN INJURY}

Some of the biological aspects of PTSD interface with the pathophysiology of TBI. This section of the article will examine genetic contributions, structural changes, endocrinological changes, and neurochemical changes found in PTSD. The findings will then be applied to TBI, followed by a brief summary of the implications of the overlap between PTSD and TBI.

\section{Genetic Contributions}

\section{Genetic Aspects of Posttraumatic Stress Disorder}

The first question to be addressed is, "Does PTSD have a genetic contribution?" Several studies illustrate 
that it does. In one study, adult children of Holocaust survivors with PTSD exhibit an increased prevalence of PTSD even though these children as a group did not have greater exposure to life-threatening events [113]. However, subsequent research questions whether these findings are attributable to genetic vulnerability or mediated by increased rates of childhood abuse and neglect [114]. In the DSM-III-R (revised) Anxiety Disorders Twin Study, PTSD was found only in cotwins of anxiety probands. PTSD was twice as prevalent in monozygotic twins, being noted in 20 percent, while it was observed in only 7 percent of dizygotic twins [115].

The most well-known Department of Veterans Affairs (VA) study illustrating a link between PTSD and genetics is the Vietnam Era Twin Registry [116]. It was composed of middle-aged male-male twin pairs, both of whom served in the military during the Vietnam war. This analysis adjusted for differences in combat exposure. No evidence was found that a shared environment contributed to the development of symptoms. The genetic contributions to variance of liability for each symptom cluster were found to be reexperiencing (13\%-30\%), avoidance (30\%$34 \%)$, and arousal (28\%-32\%) [116].

The next question to consider after establishing a genetic contribution to PTSD is, "Which genes are involved?” In considering neuropsychiatric syndromes such as PTSD, this process is complicated in that such syndromes usually follow a non-Mendelian inheritance pattern. An oligogenic pattern may exist in which more than one gene collaborates to produce a phenotype or a heterogeneity in which similar phenotypes may arise from different genotypes. Identifying specific genes is further complicated by incomplete penetrance, pleiotropy (multiple effects of a single gene), and epistatic interactions (several genes interacting in the same individuals) [115]. The psychiatric comorbidities and range of family psychiatric syndromes further complicate analysis.

Traditional techniques for identifying genes are limited. The most traditional genetic study technique to identify contributing genes is with a linkage study. No linkage studies have documented investigating the genetics of PTSD, but two association studies have investigated it. One of these identified an association between PTSD and the A1 allele of the DA-2 receptor gene. The other study did not replicate this finding [117]. Newer techniques are focusing on identifying biomarkers and attempting to associate genes specific to the biomarker so that an overlap may be found within the actual genetic coding of the syndrome itself [118].
From the emerging field of epigenetics comes the observation that severe maternal stress in pregnancy can affect the HPA axis of the offspring with changes similar to that found in PTSD. These changes in the HPA axis have even been observed in the next generation offspring unexposed to maternal stress or exogenous glucocorticoids [119]. Whether the stress from TBI can have a similar effect on the HPA axis of offspring is unclear.

\section{Genetics of Traumatic Brain Injury}

Several genetic observations in TBI have been observed. Some of the most interesting observations involve the ApoE4 allele. In one study looking at boxers, patients with TBI who also had the ApoE4 allele appeared to have more severe cognitive impairment and neurological deficits [120]. Teasdale et al. demonstrated that ApoE4 was associated with a poorer outcome as measured by the Glasgow Outcome Scale 6 months postinjury [121]. Millar et al. also demonstrated strong associations between the ApoE4 allele and a poor neuropsychological outcome [122].

This particular linkage to ApoE4 relates to certain pathophysiological changes. ApoE4 was traditionally linked to a higher risk of developing Alzheimer's disease. Head injury is a known risk factor for Alzheimer's disease. ApoE4 is likely to exert its effects through modification of protection and repair mechanisms.

\section{Implications}

Genetic studies of PTSD suggest that a hereditary predisposition to vulnerability following a trauma may exist in some cases. Similarly, some cases of TBI have demonstrated that possession of the ApoE4 allele influences recovery following TBI.

\section{Structural Changes}

\section{Posttraumatic Stress Disorder}

Most of the information regarding structural changes in humans comes from neuroimaging studies, including both structural and functional imaging. An extensive literature can also be found on structural changes in animal models.

Structural Imaging. Some studies have noted an increased incidence of white matter changes in cavum septum pellucidum and contusions from movement across the bony protrusions at the base of the skull. Volumetric studies have demonstrated a higher ventricle in 
patients with PTSD: brain ratio with greater sulcal widening [123]. The most compelling finding, however, is the observation of hippocampal atrophy. This atrophy is observed not only with volumetric studies but also with magnetic resonance spectroscopy studies in which reductions in $\mathrm{N}$-acetylaspartate correlate with reduced density or viability of neurons. Specifically, an 18 percent decrease has been found in the right hippocampus (the relay distributor of sensory information to the cortex) of Vietnam veterans [123].

Hippocampal atrophy in PTSD has been the topic of many volumetric studies. It has been observed to be a right-sided phenomenon in combat veterans and a leftsided phenomenon in women with childhood sexual abuse [124]. One study identified patients with PTSD with bilateral hippocampal atrophy. This finding appears to correlate with neuropsychological studies in PTSD that demonstrate decreased short-term memory on formal testing [125]. Interestingly, hippocampal atrophy in PTSD does not occur in children and is not seen in the first 6 months after trauma.

Functional Imaging. Many studies have investigated the correlations of functional imaging to PTSD. Positron emission tomography (PET) studies of PTSD patients reveal decreased blood flow to the medial prefrontal cortex and increased blood flow to areas of memory and visuospatial processing as compared with nondisabled subjects [126]. Decreased blood flow to the frontal areas of the anterior cingulate gyrus and the medial frontal gyrus has also been observed in studies using functional magnetic resonance imaging (fMRI) [127]. Decreased frontal function in PTSD is further supported by ligand studies that found benzodiazepine binding is decreased 41 percent in patients with PTSD [128].

While PET and fMRI have demonstrated decreased frontal activity in patients with PTSD, studies with singlephoton emission computed tomography have demonstrated increased activity in the amygdala (the "vigilant sentry" that monitors all sensory input). However, this increased activity is not observed with direct visual stimuli [123]. The amygdala is noted to be modulated by the prefrontal cortex (the region for discrimination and inhibition of responses). With decreased prefrontal activity, a lowered modulation for activation of the amygdala results.

Histology from Animal Models. Experimental evidence shows that stress induces structural changes in neuronal networks [129]. These changes are evident in the amygdala, the hippocampus, and the prefrontal cortex. In the amygdala, stress can elicit dendritic hypertro- phy, indicating increased sensitivity to input. Within the hippocampus, stress exposure results in remodeling of dendrites of the CA3 pyramidal neurons and in reduced numbers of synapses on those neurons. Furthermore, stress inhibits adult neurogenesis (the growth of new neurons from stem cells to replace neurons that have died off) in the dentate gyrus. In the prefrontal cortex, repeated exposure to stress causes dendritic retraction and loss of spines of the pyramidal neurons. Moreover, molecular studies cited by Fuchs et al. show that stress modulates expression of genes involved in neuronal differentiation and/or structural remodeling [129]. Astroglia in the hippocampus are also reduced by stress [130]. Several investigators have suggested that these changes are initially adaptive responses to the changing requirements from the external and internal environments. At the behavioral level, increased vigilance and rapid, "automatic" response are positive survival tactics in extremely dangerous places such as combat zones and disaster sites.

Animal models of chronic stress have shown rapid atrophy ("pruning") of the dendritic "twigs and branches" of the hippocampal neurons. Furthermore, these dendrites can regenerate almost as quickly as they disappear. In hamsters, removing an intense psychosocial stressor that had caused extreme pruning allowed a rapid "rearborization." The cellular reorganization (recovery) following stressinduced hippocampal damage in rats correlated with recovery of stress-induced cognitive deficits [131].

Human PTSD is closer to the animal models of aversive one-trial learning than to chronic stress, although the painful intrusive memories and the hyperarousal symptoms are chronic stressors as well. Human memory, and perhaps specific "cognitive hooks" that make the memories intolerably painful and self-perpetuating, may speed hippocampal atrophy and amygdala hypertrophy in some individuals by driving biological processes. Persistence of such memories and cognitive frameworks could inhibit the recovery process and prevent the rapid rearborization of dendrites in the hippocampus and prefrontal cortex and corresponding "demobilization" of hypertrophied dendrites in the amygdala. Evidence now suggests that both pharmacotherapy and effective psychotherapies may stimulate hippocampal neurogenesis and the regrowth of dendritic connections.

\section{Traumatic Brain Injury}

Studies of the biomechanics and pathophysiology of TBI have demonstrated that, regardless of the direction of force, the most affected structural areas of the brain are 
the frontal lobes and the temporal lobes [132]. These areas are more affected because of the coup-contrecoup mechanism of injury and the movement of brain across the bony protrusions of the basal skull. This finding is particularly relevant because of the vulnerability of some anatomical structures of the temporal lobe such as the amygdala and the hippocampus. ${ }^{*}$ The prefrontal damage is associated with decreased inhibition of anxiety following a TBI.

Studies have shown that concussive brain injury, with its chemical cascade of excessive neuroexcitation that injures neurons, combined with deafferentation of input to the hippocampus from lesions (e.g., contusion) in the frontal cortex and temporal poles alter the hippocampal plasticity and the pattern of dendritic structural reorganization and axonal sprouting [133]. This alteration is occurring in the same regions where PTSD is also provoking neuronal reorganization.

\section{Implications}

The areas of dysfunction in PTSD appear to be the anterior cingulate and medial frontal gyri within the frontal lobes as well as associated hippocampal atrophy. The hippocampi and amygdala are located in the medial area of the temporal lobes. Therefore, the areas of the brain that are most vulnerable to TBI are also the same areas that are most involved with dysfunction in patients with PTSD.

\section{Endocrine Findings}

\section{Hypothalamic-Pituitary-Adrenal Involvement in Posttraumatic Stress Disorder}

Many studies have shown cortisol levels observed in PTSD. These studies evaluate the axis between the hypothalamus, the pituitary gland, and the adrenal gland. The hypothalamus signals the pituitary gland with the release of corticotrophin-releasing factor (CRF). The pituitary signals the adrenal gland with the release of adrenocorticotropic hormone (ACTH). Cortisol is released by the adrenal gland and allows the body to physiologically adapt to stress. A classic stress response has elevated CRF, ACTH, and cortisol levels. Cortisol mediates its

\footnotetext{
*Kelly JP. The diagnosis and management of concussion [lecture]. Presented at 2004 American Academy of Neurology annual meeting; 2004 Apr 24-May 1; San Francisco, CA.
}

effects by binding to glucocorticoid receptors. These receptors are decreased in chronic stress and depression.

Subjects with PTSD have alterations in their HPA axis. For example, they have low cortisol levels and high CRF levels. Previously, the low levels of cortisol were attributed to "adrenal burnout," which means that they were thought to be elevated with the acute trauma and then burned out to lower levels [134]. Emergency room studies of acute measures of cortisol 1 to 2 hours following a trauma show lowto-normal levels in patients subsequently diagnosed with PTSD [55,82]. Studies of patients with PTSD have demonstrated that these patients have both an increase in the quantity of receptors as well as an increase in the sensitivity of these receptors. These receptor changes allow for enhanced negative feedback inhibition of cortisol at the pituitary gland, which signals less ACTH to be released and the attenuation of cortisol. Chronically elevated levels of CRF may also alter pituitary responsiveness to other pituitary hormone signals [135].

\section{Traumatic Brain Injury-Related Pituitary Dysfunction}

Up to 50 percent of patients with TBI have impaired neuroendocrine function. Of these, 20 percent have a combination of two or more deficiencies. Many of these are transient. When the initial injury is severe enough to cause a panhypopituitary state, pituitary function does not usually recover. The most common pituitary dysfunction associated with TBI is growth hormone deficiency. This finding was observed in 15 percent of subjects. It provides a diagnostic challenge because some of the symptoms may overlap with those of postconcussion syndrome [136].

The pathophysiology of the pattern of TBI-related pituitary dysfunction may suggest a hierarchy of vulnerability to trauma of pituitary cells. The most vulnerable cells include somatotrophs and gonadotrophs. These cells are located more in the lateral wings of the pituitary gland. Additionally, they are supplied primarily by the long hypophysial portal system, which is more vulnerable to trauma because it passes through the diaphragm of the pituitary [137].

More resilient cells include corticotrophs and thyrotrophs. These cells are located more in the central portion of the gland and are supplied by the short hypophysial portal system [137].

\section{Implications}

PTSD and TBI are both associated with decreased function of the pituitary gland. In PTSD, this decreased 
function is based primarily on the increased sensitivity and number of glucocorticoid receptors causing increased negative feedback on the pituitary gland. TBI patients commonly have impaired function of the pituitary due to the decreased release of hormones, most commonly from the most vulnerable pituitary cells (somatotrophs and gonadotrophs).

\section{Neurochemical and Neurotransmitter Changes}

\section{Posttraumatic Stress Disorder}

Many neurotransmitter and neurochemical pathways in PTSD are dysregulated. Of these, the most compelling evidence surrounds serotonin. This serotonergic dysregulation may account for the selective serotonergic reuptake inhibitors (SSRIs) appearing to have the most efficacy for symptoms of PTSD [138]. Patients with PTSD have their symptoms activated pharmacologically by the serotonin agonist, $m$-chlorophenylpiperazine [139]. Therefore, the efficacy of SSRIs may not be from increasing serotonin but from their modulation of serotonin transporters or their effects on the modulation and release of many other neurotransmitters, to include the noradrenergic neurotransmitters.

PTSD has several noradrenergic aspects. The baseline prefrontal cortex inhibition of the amygdala is impaired by postsynaptic alpha-1 receptors at higher levels of norepinephrine release. The amygdala mediates its memory enhancement of emotionally arousing events via beta receptors. The stimulation of these receptors is what accounts for the increased acoustic startle in patients with PTSD. Of interest, the increased startle response is not noted acutely. Its onset occurs between the first week and the first month. This may imply a dynamic progression in pathophysiology. Memory retrieval of a traumatic event increases norepinephrine release. All these factors lead to a positive feedback loop contributing to the "overconsolidation" of a traumatic memory [140].

Changes in the sympathetic nervous system include increased activation that exists in a phasic rather than tonic pattern. Decreased alpha-2 receptors have been observed with the alpha-2 antagonist, Yohimbine, able to induce PTSD symptoms in some patients. Changes have also been observed in the parasympathetic nervous system as evidenced by heart rate variability in the first month following a traumatic event [139].

Changes in glutamate and gamma-aminobutyric acid (GABA) have also been observed. Activation of glutamate is increased, which is involved in encoding memory. In an extreme stress setting, GABA is downregulated with a subsequent decrease in negative modulation [140].

\section{Traumatic Brain Injury}

A "storm" of neurotransmitter release is in the setting of TBI. This release disrupts function of the brain areas in which they have significant roles.

Acetylcholine may have the most significant effects. It is considered critical for support of function in the reticular formation (arousal and attention), the entorhinal-hippocampal formation (declarative memory), and frontalsubcortical circuits (executive function). Acute activation of acetylcholine neurons leads to a decreased function of acetylcholine. The result is a decrease of synthesis, as well as acetylcholine neurons [141]. The decease in acetylcholine is thought to be the neurochemical basis for the cognitive deficits exhibited following TBI [142]. Further support of the cholinergic contribution to cognitive aspects of TBI is provided by studies of sensory gating, a parameter of attention that uses acetylcholine [143].

The increase in serotonin seen in TBI may be associated with the depression in cerebral glucose utilization in areas of damage from the TBI. The most sensitive areas to serotonin include the limbic areas and the frontalsubcortical circuits [144]. Noradrenergic neurotransmitter systems have also been found to be dysfunctional. Sometimes the cholinergic deficit causes noradrenergic dysfunction secondary to the lost modulation effect from acetylcholine. Sometimes, the absolute loss of noradrenergic projections is mild, but the effects are exaggerated, because of variations in the metabolism due to genetic variability of the catechol-o-methyltransferase enzyme [145]. The glutamate is also involved, which is the principal excitatory neurotransmitter thought to facilitate information processing. TBI is associated with persistent damage and dysfunction to areas with dense glutamate receptors [146]. This glutamate is the traditional neurotransmitter associated with excitotoxicity.

\section{Implications}

PTSD is associated with a dysregulation of neurotransmitter pathways. Based on efficacy of treatment with SSRIs, serotonin may be one of the more important neurotransmitters involved. TBI also is related to acute pathological neurotransmitter release followed by dysfunction of neurotransmitter systems. Acetylcholine appears to have the most significant effects on cognition. 


\section{Conclusions}

A biological interface appears to be between TBI and PTSD. Many of the genetic, structural, endocrine, and neurochemical changes of TBI appear to have similar changes noted in the pathophysiology PTSD. Some of these changes may enhance the biological risk of a patient with TBI developing PTSD or a PTSD-like syndrome.

\section{COMORBIDITY OF POSTTRAUMATIC STRESS DISORDER AND OTHER MENTAL DISORDERS AND INTERFACE WITH TRAUMATIC BRAIN INJURY}

PTSD is often comorbid with other mental disorders, as defined by the DSM of Nervous and Mental Diseases. High rates of comorbidity for PTSD is indicated by the NCS [147], the largest epidemiological study of the general population of the United States. Analyses of the data from this study show that 44 percent of the women and 59 percent of the men who meet the screening criteria for PTSD (lifetime prevalence) also meet the screening criteria for three or more other mental disorders in their lifetimes. Only 21 percent of women and 12 percent of men have only PTSD (Table 1) [25,147]. Other studies have found similar multiple comorbidities in selected populations.

The most common comorbid conditions with PTSD in the NCS (Table 2) are depressive disorders (in about $70 \%$ of men and women) [147]. Substance abuse disorders are also prominent, with alcohol abuse in about half of men and other drugs in about a third (much lower in women). Other anxiety disorders also occur frequently in people who have PTSD in their lifetimes (higher in men), although for these, the diagnostic differentiation from PTSD itself is more complicated, as will be discussed.

Of course, lifetime comorbidity does not mean that the other disorders were necessarily concurrent with the PTSD. However, a review of studies that looked at concurrent PTSD and depression found concurrences ranging from 30.1 to 64.5 percent [149]. Substance abuse also frequently complicates active PTSD [150].

Why should PTSD have so much comorbidity? Brady et al. addressed this question by delineating and discussing several causal pathways by which PTSD can be associated with other disorders [147]. The article reviews scientific studies and statistics relevant to the hypothesized causal models. The null hypothesis is that the simultaneous presence of PTSD and another diagnosis
Table 1.

Lifetime comorbidity of posttraumatic stress disorder with other mental disorders.

\begin{tabular}{ccccc}
\hline $\begin{array}{c}\text { No. of Other } \\
\text { Mental } \\
\text { Disorders }\end{array}$ & $\begin{array}{c}\text { Women } \\
(\mathbf{\%})\end{array}$ & $\begin{array}{c}\text { Odds } \\
\text { Ratio } \\
\mathbf{( \% )}\end{array}$ & $\begin{array}{c}\text { Men } \\
\mathbf{( \% )}\end{array}$ & $\begin{array}{c}\text { Odds } \\
\text { Ratio } \\
\mathbf{( \% )}\end{array}$ \\
\hline 0 & 21 & 0.2 & 12 & 0.2 \\
1 & 17 & 2.2 & 15 & 2.4 \\
2 & 18 & 4.0 & 14 & 3.8 \\
$3+$ & 44 & 7.9 & 59 & 14.5 \\
\hline
\end{tabular}

Source: Data from Kessler RC, Sonnega A, Bromet E, Hughes M, Nelson CB. Posttraumatic stress disorder in the National Comorbidity Survey. Arch Gen Psychiatry. 1995;52(12):1048-60. [PMID: 7492257]

Table 2.

Frequency (\%) of prominent lifetime comorbid mental disorders with posttraumatic stress disorder of persons aged $15-54$ years $(N=5,877)$.

\begin{tabular}{lrc}
\hline \multicolumn{1}{c}{ Types of Disorders } & Men & Women \\
\hline Depressive Disorders & & \\
Major Depression & 47.9 & 48.5 \\
Dysthymia & 21.4 & 23.3 \\
Substance Use Disorders & & \\
Alcohol Abuse/Addiction & 51.9 & 13.5 \\
Drug Abuse/Addiction & 34.5 & 7.6 \\
Other Anxiety Disorders & & \\
Simple Phobia & 31.4 & 14.5 \\
Agoraphobia & 16.1 & 7.8 \\
Social Phobia & 6.0 & 14.1 \\
Generalized Anxiety Disorder & 16.8 & 7.6 \\
Panic Disorder & 7.3 & 4.3 \\
\hline
\end{tabular}

Source: Data from Kessler RC, Sonnega A, Bromet E, Hughes M, Nelson CB. Posttraumatic stress disorder in the National Comorbidity Survey. Arch Gen Psychiatry. 1995;52(12):1048-60. [PMID: 7492257]

is coincidental, with each disorder having fully independent causes. Statistically, this hypothesis is likely in varying degrees but adds little to understanding or treating the disorder.

For some cases of PTSD, the history indicates that another mental disorder was present before the PTSD and increased the likelihood that the individual would encounter traumatic events. For example, individuals who abuse substances or experience a manic episode may put themselves into situations with increased risk of injury or death. Some personality traits and disorders (stimulus and riskseeking, antisocial, narcissistic, paranoid) may feature reckless behaviors that cause traumatic consequences or aggressive behaviors that provoke physical retaliation. 
Other individuals may involve themselves with interpersonal relationships or situations in which they are prone to be abused.

A variation of this explanation for comorbidity is that a preexisting mental disorder (with its underlying biopsychosocial predispositions) may increase the susceptibility of an individual to develop PTSD when a potentially traumatic event occurs. Some individuals are remarkably resilient against PTSD, even in horrendous situations, while others appear highly vulnerable. Some people are so predisposed that they get "vicarious PTSD" from hearing about or seeing traumatic events through the media that happened to strangers. An example of this causal pathway would be seen in an individual with generalized anxiety disorder, prone to worry, overgeneralization, and catastrophizing who naturally reacts this way to any potentially traumatic event. When a patient's preexisting mental disorder causes the traumatic event and subsequent PTSD or makes the patient unduly susceptible to PTSD, therapists need to guard against becoming judgmental and lapsing into providing suboptimal care because they unconsciously ascribe blame to the individual.

A suggestion has been that dissociative traits may predispose to PTSD. They could manifest earlier as clinical disorders or subsyndromal conditions such as dissociative amnesia, dissociative fugue, or depersonalization and derealization disorders. Amnesia for aspects of the trauma is one of the DSM avoidance cluster symptoms of PTSD, and depersonalization and derealization are listed as commonly associated symptoms. Such experiences during the peritraumatic period or immediately after the traumatic event is included in the DSM diagnosis of ASD because they are hypothesized to predict PTSD a month or more after the trauma. However, Briere et al. found that unlike persistent trauma-related dissociation, peritraumatic dissociation does not predict PTSD [151].

Another pathway describes symptoms of a comorbid mental disorder as an alternative to express the persistent fear, horror, or helplessness of a traumatic event. For example, in some individuals, posttraumatic symptoms may present as somatization psychopathology rather than ASD or PTSD [152]. In some non-Western cultures, most forms of mental distress are expressed socially as somatic symptoms rather than as emotions. Conversion reactions are also common in such cultures.

Another causal pathway for comorbid mental conditions is found in the overlapping symptoms of PTSD and other DSM diagnoses. This pathway implies that the symptoms may be caused by the same neural pathways and neuroendocrine interactions. A prominent example is the overlapping symptoms between PTSD and other anxiety disorders. Literature has cited these disorders as among the more common comorbidities. The overlap of criterion symptoms is notable between PTSD and panic disorders, social phobia, agoraphobia, and specific phobias. The only anxiety disorder symptoms that are not common in PTSD are obsessive compulsive ones, and here the apparent concordance of those two diagnoses does appear to be largely because of the overlap of the shared nonspecific symptoms [153].

Recognizing the symptoms of panic disorder, agoraphobia, and social phobia is important. Specific phobias and obsessive compulsions embedded in PTSD, because they can be targets of tailored psychotherapies. Conversely, asking persons with those disorders whether they have had traumatic experiences is important, because they may not volunteer the information.

Although the DSM states specifically that the diagnosis of intermittent explosive disorder should not be used when it is caused by another mental disorder, the irritability and angry outbursts of PTSD can lead to impulsive violent responses that destroy property or injure individuals. PTSD can include increased aggressive behavior that is frequently impulsive and episodic, as well as a reduced ability to tolerate provocations, resulting in disproportionate reactions [152]. This potential is sufficient to warrant "risk reassessment" by therapists (including physical and occupational therapists), especially when deadly weapons are freely available and alcohol or substance abuse is present.

In another causal pathway, PTSD may increase the likelihood or "cause" another mental disorder. A frequently cited example is the link between PTSD and substance abuse disorders-the so-called "self-medication hypothesis." This hypothesis is supported by evidence that alcohol use commonly increases soon after the traumatic event [150]. However, persons with PTSD who were well-controlled social users, or abstainers on principle, often begin to drink alone every evening. If asked, they say that the alcohol helps them relax and fall asleep and reduces the bad dreams they have been having. Regrettably, the alcohol may also cause early awakening (i.e., more sleep disturbance, which is already characteristic of PTSD, TBI, and major depression). Sleep deprivation itself impairs memory and concentration and increases irritability and emotional ability. Indeed, sleep 
deprivation in TBI, PTSD, and major depression can significantly contribute to the cognitive impairment and behavioral problems. The other drawbacks of alcohol self-medication for PTSD are that it progressively requires more ingestion to relax, directly impairs judgment and impulse control, and further unleashes the irritability and anger already latent in TBI and PTSD.

PTSD can also cause depression via a pathway involving guilt [152]. Guilt is a common associated symptom of depression. The guilt may be from what the person did or did not do to survive and escape the terrifying, horrifying, or helplessness-producing threat to life or bodily integrity. The survivor or victim, and others, may judge their actions as stupid, negligent, cowardly, selfish, evilly aggressive, etc. They may become stuck in endless ruminations about "Why didn't I . . ." or "If only I had ...." and blame themselves for things they could not possibly have foreseen or controlled. That leads to, "I deserved what happened to me.” The guilt may also be existential: "Why did I survive when others more worthy did not?” The guilt may be attributed to others in ways that shatter their faith in the ultimate goodness of people or agencies on which they depend.

Such guilt and feelings of hopelessness and learned helplessness are naturally depressogenic to the nervous system. What started as normal negative feelings can worsen into adjustment disorder with depressed mood (perhaps also with mixed anxiety and disturbed behavior). It may worsen further into major depression. A prior history of depression increases the likelihood of developing a major depressive episode and also increases the likelihood of more severe associated symptoms. However, in some studies cited in Brady et al. [147], analysis has indicated that PTSD and major depression were correlated by independent responses to trauma. One can fairly say that PTSD and depressive disorders are closely related, but the nature of the response is complex and varies case by case. Special attention should be paid to the danger of suicide in persons with PTSD. The risks for attempting initial suicide, attempting an impulsive suicide, and planning a suicide are high [154].

Comorbidities can challenge the treatment of PTSD, even more so in the presence of recovery from TBI. Overlapping symptoms of particular relevance to this article occur among PTSD, TBI, and major depression. These all share the symptoms of sleep disruption, difficulty concentrating and attending, slowed thinking, and memory impairment. This is an overlap of great practical signifi- cance, because arousal in the causal pathway of one disorder can cause another disorder, leading to additional clinical complexity and potentially deteriorating psychological and physiological status. The cognitive impairment and behavioral disturbance from PTSD and from TBI are likely to have social and occupational consequences, and perhaps even a legal one: medical separation for military personnel, loss of job or unemployability, relationship strife and divorce or breakup, charges for traffic violations, assault, or drug abuse. These may increase anger, anxiety, and/or depression. The cognitive impairment is often more demoralizing and stigmatizing than an obvious physical disability.

\section{Effect of Identifying Comorbidities}

Multiple DSM diagnoses clarify each manifestation and justify and provide focus for multiple treatments. These diagnoses can be necessary to cover the time and expense of treatments that are specific to a symptom manifestation, especially if they involve different trained therapists, workload documentation for staffing, and/or third party payment. Multiple diagnoses are more likely to qualify the patient for potential disability benefits, which is justifiable if the diagnoses cause cumulative rather than overlapping disability. On the down side, the presence of multiple diagnoses can convince the patient that he or she is sicker and more disabled. Illness behaviors for secondary gain can be fostered, unconsciously or deliberately. A long list of diagnoses can negatively affect the impressions and reactions of caregivers, family members, medical board members, insurance companies, and potential employers.

When comorbid symptoms need to be identified separately, some of the drawbacks of multiple diagnoses can be avoided with a DSM diagnosis that implies good prognosis. Adjustment disorder with depressed mood and even adjustment disorder with depression, anxiety, and disturbed conduct highlight those symptoms for treatment while recognizing them as consequences of the difficult adjustment to TBI, other physical disabilities, cognitive limitations, posttraumatic memories, and other psychological challenges.

\section{Implications of Posttraumatic Stress Disorder Comorbidity for Treatment}

Identifying comorbid conditions that accompany PTSD can assist the clinician who is treating the patient 
with PTSD. Multiple diagnoses can have several specific effects on treatment, as listed in the following:

1. Awareness of the probability of comorbidity improves the diagnostician's and therapist's recognition of multiple diagnoses when they occur.

2. Recognition of comorbidities can enhance understanding and empathy for "difficult" patients.

3. Recognition may identify reasons for slow functional improvement or "noncompliance."

4. Recognition and understanding enables tailoring the approach to the patient in physical and occupational rehabilitation.

5. Recognition of the patient's individual vulnerabilities and needs can mobilize ancillary methods/services, as discussed in the next section on treatment.

6. Recognition may justify clinical referral for further evaluation and treatment of the PTSD and/or of the comorbid condition.

\section{TREATMENT OF POSTTRAUMATIC STRESS DISORDER IN CONTEXT OF MILD TRAUMATIC BRAIN INJURY}

As noted, a significant overlap exists between TBI and PTSD, primarily in cognitive, emotional, and behavioral functions. With current clinical and scientific knowledge regarding the comorbidity of PTSD and TBI, we can only speculate whether the impairments caused "independently" by each source might be additive or multiplicative or might create a "ceiling effect," where the sum of the two is less than would be predicted for each alone. A purely speculative example would be that memory impairment is additive (i.e., worse memory overall); irritability, anger, and violence is multiplicative (especially given frontal lobe damage resulting in disinhibition); and concentration or distraction impairment reaches a ceiling. In addition, the possibility of a "protective" effect exists, whereby the inability to recall aspects of the emotionally traumatic event actually protects the individual from memory or recall of the event. In practice, no scientifically demonstrable "universal" effects may exist until we have reliable objective evidence of the degree (severity) of neuronal changes related to specific injury type and traumatic stressor. For now, we must consider the practical, clinical questions and subject them to vigilant clinical observation and scientific investigation. These questions include-

- Can treatments that work for PTSD symptoms without TBI also improve those symptoms when they have a strong causal component from TBI?

- Can comorbid TBI render some treatments for PTSD potentially harmful?

- Can PTSD complicate the treatment and rehabilitation of TBI?

Only a few studies have addressed treatment of cooccurring TBI and PTSD. Bryant et al. compared a cognitive-behavioral therapy (CBT) regimen versus supportive counseling for the treatment of ASD and mild TBI [155]. Treatment consisted of (1) psychoeducation about the nature of posttraumatic reactions and symptoms, (2) relaxation training, (3) imaginal exposure to reexperiencing symptoms, (4) cognitive restructuring, and (5) graded in vivo exposure to fear-provoking situations. The CBT group was compared with a supportive counseling group of psychoeducation about traumatic reactions and problem solving skills. Results suggest marked reduction of intrusive memories and avoidant behaviors in the CBT group as compared with the supportive counseling group. The CBT patients had significantly less PTSD than the supportive counseling group at posttreatment evaluation ( $8 \%$ vs $58 \%$, respectively) and at 6-month follow-up (17\% vs 58\%, respectively).

Another interesting finding of the Bryant et al. study was that partial PTA following the incident did not necessarily reduce the efficacy of the exposure or cognitive therapy [155]. Furthermore, depressive symptoms, commonly seen after TBI, did not appear to respond to either the CBT or supportive counseling. This finding suggests that additional attention be placed on monitoring depressive symptoms, including thoughts of suicide, even in survivors of head injury who receive acute stress interventions [156]. Important to note is that subjects in the Bryant et al. study were diagnosed with ASD and not PTSD [155]; however, the results do suggest that CBT may be effective with individuals with at least a mild TBI. Moreover, this study is limited because of a small sample size, as well as the mild nature of the head injuries and cognitive impairments. A separate report of two cases treated with CBT for PTSD after more severe TBI has shown efficacy in management of mood state and redeveloping social roles as well as reduction in PTSD symptoms [157].

While clinical guidelines for the treatment of cooccurring TBI and PTSD are not yet available, several 
resources are available to care for the catastrophically injured and emotionally traumatized. Physicians, nurses, psychologists or neuropsychologists, and support staff who provide tertiary care for the war wounded must be knowledgeable and equipped for the emotional reactions that may accompany blast concussions. What follows are descriptions of several resources that provide comprehensive treatment approaches for active duty soldiers and veterans, as well as an overview of the current empirically validated clinical treatment protocols available for TBI and PTSD.

One of the most rigorous recent initiatives to examine treatments of PTSD is the DOD/VA Clinical Practice Guidelines (CPG) for the management of PTSD [158]. Several other resources are available, including the VA's Veterans Health Initiatives on Caring for War Wounded, PTSD: Implications for Primary Care and Traumatic Brain Injury [159].

\section{Pharmacotherapy Interventions}

The following pharmacotherapy recommendations and discussion are based on the VA/DOD CPG. Antidepressants have proven effective for treating PTSD, especially SSRIs, and are recommended in the VA/DOD CPG. The SSRIs are considered "strongly recommended" as having significant benefit for treating PTSD. They have relatively acceptable side effects and wide safety margins for overdose. Of all SSRIs, sertraline has been researched the most. Four studies that each included more than 100 subjects demonstrated a significant positive response to sertraline. The Food and Drug Administration has approved both sertraline and paroxetine for treating PTSD. Fluoxetine has also been shown to be useful, and although less studied to date, both citalopram and fluvoxamine are also potential agents for addressing PTSD symptoms.

The tricyclic antidepressants are also recommended; however, compared with the SSRIs, these have more troublesome side effects and lower safety margins. The monoamine oxidase inhibitors are also recommended in the CPGs, but they have potentially troublesome side effects, require lengthy "washout periods" before starting a range of other medications, require avoidance of CNS stimulants and decongestants, and require following a strict diet that avoids foods containing tyramine. The atypical antidepressants (e.g., bupropion, nefazedone, trazodone, venlafaxine) "may be considered." The guidelines recommend that a therapeutic trial of an antidepressant for symp- toms of PTSD should be at least 12 weeks before changing to another therapeutic regimen. The sympatholytics are also recommended because they block the peripheral autonomic hyperarousal in PTSD, but they can also cause troublesome side effects, including hypotension. Prazosin has been reported to be effective for treating nightmares associated with PTSD [160-161], although in much lower doses than are used to treat hypertension.

To date, insufficient evidence exists to recommend anticonvulsants, mood stabilizers, atypical antipsychotics, buspirone, and nonbenzodiazepine hypnotics. The CPG state that they may be helpful in selected cases, alone, or as adjunctive treatment. The anticonvulsants (e.g., carbamazepine, gabapentin, valproate) are prescribed for the PTSD and TBI shared symptoms of irritability, flash anger, and potential violent outbursts. Quetiapine, an atypical antipsychotic, is prescribed in practice for the insomnia, which is common in both PTSD and TBI. Zolpidem may be used less now than previously because of concern for its reported side effects of sleepwalking (including nocturnal compulsive eating) and amnestic episodes that continue after the patient awakens. Comorbid TBI could cause the patient to be significantly more sensitive to these effects. The long-term use of benzodiazepines and the older "typical" antipsychotics for PTSD is rated in the practice guidelines as not useful and even potentially harmful.

In general, TBI may cause the patient to be more sensitive to side effects or to the main effects of many medications. This finding can be true for psychotropic medications as it reportedly is for alcohol, which is sometimes used in excess by individuals with PTSD. When initiating any medication for a patient with TBI, one should be prudent and start at a lower dose and observe closely during a gradual increase to a therapeutic dose.

Drug interactions also require special vigilance in patients with TBI, because the impaired brain function (and other aspects of metabolism if multiple injuries are present) may compound them. Patients with TBI and comorbid PTSD (and perhaps depression and other psychiatric conditions) may already be taking medications for headache, dizziness, orthopedic pains, insomnia, allergies, etc. If they have burns, wounds, internal organ injuries, or amputations, they may undergo multiple procedures and surgeries with anesthesia, antibiotics, and fluid/electrolyte challenges. The home caregivers, prescribing providers, and rehabilitation staff should actively query the patient about possible adverse drug reactions. 
Both PTSD and TBI can impair memory and concentration, so patients may be prone to forgetfulness, misremembering, or confusing dosages, especially if they are taking several different medications (some of similar appearance) at different times of the day. The patient may need help with setting out the daily or weekly dosages in clearly marked compartments and having reminders built into the schedule of the day. Prescribing providers and other rehabilitation personnel should routinely confirm that the patient remembers, understands, and complies with the medication regimen.

Pharmacotherapy may be used along with psychotherapy, with the possibility of improving treatment compliance and outcome. Although a recent review of available randomized clinical trials found no studies that met review criteria to test the superiority of combined treatment in PTSD [162], advantages may exist, at least for certain individual cases. Even if the therapist is not also the prescribing provider, the psychotherapeutic relationship may sustain patient compliance with taking the medication long enough for determining if it is suitable for the individual. With pharmacological reduction of symptoms, the patient might be able to enter into psychotherapy that otherwise might prove too aversive to pursue. Rehabilitation therapeutic relationships can fulfill this function if the therapist is knowledgeable about the medications his or her client or patient is prescribed. These relationships could include informal use of psychotherapeutic skills and techniques by rehabilitation staff members. Successful psychotherapy may sufficiently change the meaning and behavioral basis for the posttraumatic stress reactions such that the medication can be tapered and discontinued.

\section{Psychotherapy Interventions}

The psychotherapeutic interventions with the strongest scientific support are trauma-focused CBT, which comprises varying combinations of exposure therapy and trauma-focused cognitive therapy, nontrauma-focused therapy, and eye movement desensitization and reprocessing (EMDR). CBT is a focused intervention in which the therapist guides the patient through a structured regimen that is often embodied in a manualized series of clinical treatment sessions. Many CBT interventions include some degree of psychoeducation about the stress response ("fight or flight reaction") and its impact on mental and physical performance. Most include teaching relaxation techniques so that the patient can control the intense physiological response to reminders of the trauma in PTSD and enable him or her to overcome the avoidance symptoms to proceed with the therapy. Many directly or indirectly use desensitization of negative stimuli by repeated exposure without negative consequences. The exposure can be "imaginal" (revisiting the experience in imagination and memory); "simulated" in the office by pictures, sounds, scents, etc.; "virtual” with interactive, computer-generated simulation; and/or "in vivo," by returning to the same or similar places and activities as experienced in the traumatic event.

In the cognitive component of CBT, the therapist helps the patient challenge underlying negative beliefs that the patient has about him- or herself and/or about how the "real world" works. The therapy encourages the patient to replace negative beliefs and automatic thoughts with more adaptive beliefs and assumptions. Typically, for PTSD, the process involves correcting misattribution of control and blame in the traumatic event (e.g., selfdirected guilt or other-directed rage survival actions, mistakes made, or presumed malicious intent). CBT may also involve restoring or modifying more existential beliefs about personal safety, interpersonal trust, the good and bad in human nature, as well as the possible indifference of other people.

In the behavioral component of CBT, the therapist helps guide the patient through recalling significant aspects of the traumatic event and assigns "homework" for the patient to practice activities that reinforce adaptive coping behaviors (e.g., effectively communicating with family and friends) and extinguish maladaptive behaviors (e.g., getting angry when feeling unsafe). The client learns to identify and clarify patterns of thinking by recording in a log his or her thoughts about significant, ongoing events and distressing trauma-related thoughts.

A large literature has demonstrated the efficacy of CBT treatments for chronic PTSD [163]. In addition, CBT has been shown to have specific effects on symptoms and associated features of PTSD. For example, a recent randomized trial of CBT for trauma-exposed individuals found efficacy for chronic nightmares, symptoms of depression and PTSD, fear of sleep, and sleep problems as well as improvement in sleep quality and quantity [164]. CBT has been shown to normalize the heightened heart rate reactivity to trauma-related stimuli found in PTSD patients [165].

EMDR is a therapy for which evidence of efficacy and mechanism of action is considered controversial [166]. EMDR incorporates components of other CBT 
interventions with focused attention on alternating (e.g., left and right) visual, auditory, or tactile stimuli. Simultaneously, the patient holds a multisensory image of the traumatic event (or successive associations) in mind along with a briefly worded negative cognition and later its positive replacement. Proponents believe that EMDR often works in three to five sessions for uncomplicated PTSD. Evidence suggests that EMDR is effective for PTSD compared with no treatment and with therapies not involving exposure. However, it has not shown to increase efficacy over other treatments that include exposure techniques [167]. Therefore, the efficacy of the specific eye movement component of this treatment has been questioned and results of the few studies available are inconsistent [168]. A recent report suggests that the mechanism underlying the eye movement effect involves activation of cholinergic and inhibition of sympathetic systems, similar to the pattern found during rapid eye movement sleep [168]. Whether this physiological alteration imparts an active treatment effect is unknown.

To our knowledge, no published studies exist on the use of EMDR in patients with TBI. EMDR and other forms of CBT may be difficult for patients with TBI who have impaired concentration, poor frustration tolerance, and physical symptoms, including headache and problems with vision or other senses.

Nontrauma-focused stress management has a positive but less pronounced effect in PTSD. Group treatment seems to be less effective than individual treatment. A recent metaanalysis found no significant benefits over waiting-list controls for nontrauma-focused treatments such as supportive therapy, nondirective counseling, psychodynamic therapies, and hypnotherapy [170]. Using a predetermined threshold, researchers found that only trauma-focused CBT and EMDR produced significant clinical improvements, and no major differences were found between the two in headto-head comparison studies [170-171].

A lack of literature exists on the relative efficacy of pharmacotherapy versus psychotherapy for PTSD. One recent randomized clinical trial comparing EMDR versus fluoxetine found the psychotherapy intervention to be more efficacious among individuals with adult-onset trauma. Sustained reductions were found for both PTSD and depressive symptoms, with both treatments superior to pill placebo [172].

\section{Adjunctive Problem-Focused Methods and Services}

Anywhere along the pathway from acute stress to chronic PTSD, a patient may benefit as much or more from case management and psychosocial rehabilitation as from pharmacotherapy or psychotherapy. These services are already indicated for persons with significant impairment from TBI and other physical disabilities. The Intervention Module Summary of the PTSD CPG lists adjunctive problem-focused methods and services and indicates when to initiate them. These methods and services are (1) patient education (also add caregiver and public education), (2) self-care and independent living skills training, (3) use or referral to supported housing services, (4) family skills training, (5) social skills training, (6) vocational rehabilitation training, (7) case management services, (8) access to religious or spiritual advisors and/or other resources, and (9) substance abuse treatment.

\section{New Grounds for Optimism in Treatment of Posttraumatic Stress Disorder and Traumatic Brain Injury}

Some individuals (and even cultures) can endure extreme suffering and loss without developing PTSD. Studies of the characteristics of "resilient" people seek to determine the interacting roles of (1) genetic vulnerability (or relative strength); (2) early life experiences that acclimate the neurochemical sensitivity of the stress response; and (3) the acquisition of cognitive "frames" that reduce or channel terror, hopelessness, horror, and physiological overreaction, and promote resilience and adaptive responses. However, factors also exist that work against resilience. The negative pull of disability compensation has been recognized since the late 19th century and confirmed in the aftermath of World War I in the context of "war neurosis" or "shellshock" [1]. Mercy and justness call for helping victims or survivors of traumatic events. Therefore, one challenge in treating TBI and/or PTSD is to achieve and modulate a changing balance between supportive care (including financial assistance) and the positive expectation of, and pressure toward, maximum recovery of function and independence.

\section{CONCLUSIONS}

In the context of the current war in Iraq and other global military operations in the future, understanding the neurobiological aftereffects of exposure to extreme stress, 
including resiliency, is considered a top research priority of the DOD [173]. A substantial number of injuries in our returning troops involve the head and are caused by a neurologically damaging explosive blast. The traumatic nature of injuries in the combat environment is leading to increased presence of PTSD. Future research should focus on key issues in this area, including evaluating the effect of mild TBI on the symptomatic features and PTSD development and exploring optimal identification of and treatments for PTSD after mild TBI.

\section{ACKNOWLEDGMENTS}

Dr. James W. Stokes is now with the Psychiatry Service, Department of Behavioral Medicine, Brooke Army Medical Center, Fort Sam Houston, Texas.

This material was based on work supported by the Defense and Veterans Brain Injury Center, Wilford Hall Medical Center, National Center for PTSD, Education and Clinical Laboratory, VA Palo Alto Health Care System, Palo Alto, California.

The authors have declared that no competing interests exist.

\section{REFERENCES}

1. Shephard B. A war of nerves: Soldiers and psychiatrists in the twentieth century. Cambridge (MA): Harvard University Press; 2001.

2. Gawande A. Casualties of war-military care for the wounded from Iraq and Afghanistan. N Engl J Med. 2004; 351(24):2471-75. [PMID: 15590948]

3. Kulka RA. Trauma and the Vietnam war generation: Report of findings from the National Vietnam veterans readjustment study. New York (NY): Brunner/Mazel; 1990.

4. Pitman RK, Altman B, Macklin ML. Prevalence of posttraumatic stress disorder in wounded Vietnam veterans. Am J Psychiatry. 1989;146(5):667-69. [PMID: 2785348$]$

5. Koren D, Norman D, Cohen A, Berman J, Klein EM. Increased PTSD risk with combat-related injury: a matched comparison study of injured and uninjured soldiers experiencing the same combat events. Am J Psychiatry. 2005;162(2):276-82. [PMID: 15677591$]$

6. Van Reekum R, Cohen T, Wong J. Can traumatic brain injury cause psychiatric disorders? J Neuropsychiatry Clin Neurosci. 2000;12(3):316-27. [PMID: 10956565]
7. Taber KH, Warden DL, Hurley RA. Blast-related traumatic brain injury: What is known? J Neuropsychiatry Clin Neurosci. 2006;18(2):141-45. [PMID: 16720789]

8. Gurkoff GG, Giza CC, Hovda DA. Lateral fluid percussion injury in the developing rat causes an acute, mild behavioral dysfunction in the absence of significant cell death. Brain Res. 2006;1077(1):24-36. [PMID: 16490184]

9. Cernak J, Wang Z, Jiang J, Bian X, Savic J. Ultrastructural and functional characteristics of blast injury-induced neurotrauma. J Trauma. 2001;50(4):695-706.

[PMID: 11303167]

10. Warden D. Military TBI during the Iraq and Afghanistan wars. J Head Trauma Rehabil. 2006;21(5):398-402. [PMID: 16983225]

11. Finkel MF. The neurological consequences of explosives. J Neurol Sci. 2006;249(1):63-67. [PMID: 16996540]

12. Ruff RM, Jurica P. In search of a unified definition for mild traumatic brain injury. Brain Inj. 1999;13(12):943-52. [PMID: 10628500$]$

13. Kay T, Harrington DE, Adams R, Anderson T, Berrol S, Cicerone K, Dahlberg C, Gerber D, Goka R, Harley P, Hilt J, Horn L, Lehmkuhl D, Malec J. Definition of mild traumatic brain injury. J Head Trauma Rehabil. 1993;8:86-87.

14. Silver JM, McAllister TW, Yudofsky SC. Textbook of traumatic brain injury. Washington (DC): American Psychiatric Publishing; 2005.

15. Dikemen SS, Machamer JE, Winn HR, Temkin NR. Neuropsychological outcome at 1-year post head injury. Neuropsychology. 1995;9(1):80-90.

16. Uzzell BP. Mild traumatic brain injury: Much ado about something. In: Varney NR, Roberts RJ, editors. The evaluation and treatment of mild traumatic brain injury. Mahwah (NJ): Lawrence Erlbaum Associates; 1999. p. 1-14.

17. Bernstein DM. Recovery from mild head injury. Brain Inj. 1999;13(3):151-72. [PMID: 10081598$]$

18. Rao V, Lyketsos CG. Psychiatric aspects of traumatic brain injury. Psychiatr Clin North Am. 2002;25(1):43-69. [PMID: 11912944$]$

19. American Psychiatric Association. Diagnostic and Statistical Manual of Mental Disorders. 4th ed. Washington (DC): American Psychiatric Association; 2000. p. 463-68.

20. National Center for Posttraumatic Stress Disorder [homepage on the Internet]. Washington (DC): United States Department of Veterans Affairs; c2007 [updated 2007 August 2; cited Jun 2006]. Available from:

http://www.ncptsd.va.gov/

21. McMillan TM, Williams WH, Bryant R. Post-traumatic stress disorder and traumatic brain injury: A review of causal mechanisms, assessment, and treatment. Neuropsychol Rehabil. 2003;13(1/2):149-64.

22. Feinstein A, Hershkop S, Jardine A, Ouchterloney D. The prevalence and neuropsychiatric correlates of posttraumatic 
stress symptoms following mild traumatic brain injury. Brain Cogn. 2000;44:78-82.

23. Bryant RA, Harvey AG. The influence of traumatic brain injury on acute stress disorder and post-traumatic stress disorder following motor vehicle accidents. Brain Inj. 1999; 13(1):15-22. [PMID: 9972438]

24. Hickling EJ, Gillen R, Blanchard EB, Buckley T, Taylor A. Traumatic brain injury and posttraumatic stress disorder: a preliminary investigation of neuropsychological test results in PTSD secondary to motor vehicle accidents. Brain Inj. 1998;12(4):265-74. [PMID: 9562909]

25. King NS. Post-traumatic stress disorder and head injury as a dual diagnosis: "islands" of memory as a mechanism. J Neurol Neurosurg Psychiatry. 1997;62(1):82-84. [PMID: 9010405]

26. McGrath J. Cognitive impairment associated with posttraumatic stress disorder and minor head injury: A case report. Neuropsychol Rehabil. 1997;7(3):231-40.

27. Hovland D, Raskin SA. Anxiety and posttraumatic stress. In: Raskin SA, Mateer CA, editors. Neuropscyhological management of mild traumatic brain injury. New York (NY): Oxford University Press; 2000. p. 9.

28. Kessler RC, Sonnega A, Bromet E, Hughes M, Nelson CB. Posttraumatic stress disorder in the National Comorbidity Survey. Arch Gen Psychiatry. 1995;52(12):1048-60. [PMID: 7492257]

29. Breslau N, Kessler RC, Chilcoat HD, Schultz LR, Davis GC, Andreski P. Trauma and posttraumatic stress disorder in the community: The 1996 Detroit Area Survey of Trauma. Arch Gen Psychiatry. 1998;55(7):626-32. [PMID: 9672053]

30. Kessler RC. Posttraumatic stress disorder: the burden to the individual and to society. J Clin Psychiatry. 2000;61 Suppl 5:4-12; discussion 13-14. [PMID: 10761674$]$

31. Yehuda R. Risk and resilience in posttraumatic stress disorder. J Clin Psychiatry. 2004;65 Suppl 1:29-36.

[PMID: 14728094$]$

32. Hiott DW, Labbate L. Anxiety disorders associated with traumatic brain injuries. NeuroRehabilitation. 2002;17(4): 345-55. [PMID: 12547982]

33. Koenen KC, Harley R, Lyons MJ, Wolfe J, Simpson JC, Goldberg J, Eisen SA, Tsuang M. A twin registry study of familial and individual risk factors for trauma exposure and posttraumatic stress disorder. J Nerv Ment Dis. 2002; 190(4):209-18. [PMID: 11960081$]$

34. Adler AB. Post-traumatic stress symptoms in U.S. veterans of the Gulf War. Washington (DC): Walter Reed Army Institute of Research; 1994.

35. Resnick HS, Kilpatrick DG, Dansky BS, Saunders BE, Best CL. Prevalence of civilian trauma and posttraumatic stress disorder in a representative national sample of women. J Consult Clin Psychol. 1993;61(6):984-91. [PMID: 8113499$]$

36. McMillan TM. Errors in diagnosing post-traumatic stress disorder after traumatic brain injury. Brain Inj. 2001; 15(1):39-46. [PMID: 11201313]

37. Harvey AG, Brewin CR, Jones C, Kopelman MD. Coexistence of posttraumatic stress disorder and traumatic brain injury: towards a resolution of the paradox. J Int Neuropsychol Soc. 2003;9(4):663-76. [PMID: 12755178]

38. Gil S, Caspi Y, Ben-Ari IZ, Koren D, Klein EM. Does memory of a traumatic event increase the risk for posttraumatic stress disorder in patients with traumatic brain injury? A prospective study. Am J Psychiatry. 2005;162(5): 963-69. [PMID: 15863799]

39. Levin HS, Brown SA, Song JX, McCauley SR, Boake C, Contant CF, Goodman H, Kotrla KJ. Depression and posttraumatic stress disorder at three months after mild to moderate traumatic brain injury. J Clin Exp Neuropsychol. 2001;23(6):754-69. [PMID: 11910542]

40. Klein EM, Caspi Y, Gil S. The relation between memory of the traumatic event and PTSD: evidence from studies of traumatic brain injury. Can J Psychiatry. 2003;48(1):28-33. [PMID: 12635561]

41. Mayou RA, Bryant B, Duthie R. Psychiatric consequences of road traffic accidents. BMJ. 1993;307(6905):647-51. [PMID: 8401049]

42. Price KP. Posttraumatic stress disorder and concussion: Are they incompatible? Defens Law J. 1994;43:113-20.

43. Sbordone RJ, Liter JC. Mild traumatic brain injury does not produce post-traumatic stress disorder. Brain Inj. 1995;9(4): 405-12. [PMID: 7640686$]$

44. Warden DL, Labbate LA, Salazar AM, Nelson R, Sheley E, Staudenmeier J, Martin E. Posttraumatic stress disorder in patients with traumatic brain injury and amnesia for the event? J Neuropsychiatry Clin Neurosci. 1997;9(1):18-22. [PMID: 9017524]

45. Bryant RA, Harvey AG. Acute stress response: a comparison of head injured and non-head injured patients. Psychol Med. 1995;25(4):869-73. [PMID: 7480465]

46. Ohry A, Rattock J, Solomon Z. Post-traumatic stress disorder in brain injury patients. Brain Inj. 1996;10(9):687-95. [PMID: 8853871]

47. Feinstein A, Hershkop S, Ouchterlony D, Jardine A, McCullagh S. Posttraumatic amnesia and recall of a traumatic event following traumatic brain injury. J Neuropsychiatry Clinical Neurosci. 2002;14(1):25-30. [PMID: 11884651]

48. Glaesser J, Neuner F, Lütgehetmann R, Schmidt R, Elbert T. Posttraumatic stress disorder in patients with traumatic brain injury. BMC Psychiatry. 2004;4:5. [PMID: 15113439]

49. Parker RS. The spectrum of emotional distress and personality changes after minor head injury incurred in a 
motor vehicle accident. Brain Inj. 1996;10(4):287-302. [PMID: 9044694$]$

50. Horton AM Jr. Posttraumatic stress disorder and mild head trauma: follow-up of a case study. Percept Mot Skills. 1993;76(1):243-46. [PMID: 8451132]

51. Joseph S, Masterson J. Posttraumatic stress disorder and traumatic brain injury: Are they mutually exclusive? J Trauma Stress. 1999;12(3):437-53. [PMID: 10467554$]$

52. Bryant RA, Marosszeky JE, Crooks J, Gurka JA. Posttraumatic stress disorder following severe traumatic brain injury. Am J Psychiatry. 2000;157(4):629-31. [PMID: 10739426]

53. McMillan TM. Post-traumatic stress disorder following minor and severe closed head injury: 10 single cases. Brain Inj. 1996;10(10):749-58. [PMID: 8879665]

54. Mayou RA, Black J, Bryant, B. Unconsciousness, amnesia and psychiatric symptoms following road traffic accident injury. Br J Psychiatry. 2000;177:540-45. [PMID: 11102330$]$

55. Schnurr PP, Lunney CA, Sengupta A. Risk factors for the development versus maintenance of posttraumatic stress disorder. J Trauma Stress. 2004;17(2):85-95. [PMID: 15141781]

56. McFarlane AC, Atchison M, Yehuda R. The acute stress response following motor vehicle accidents and its relations to PTSD. Ann N Y Acad Sci. 1997;821:437-41. [PMID: 9238224]

57. Shalev AY, Freedman S, Peri T, Brandes D, Sahar T. Predicting PTSD in trauma survivors: prospective evaluation of self-report and clinician-administered instruments. Br J Psychiatry. 1997;170:558-64. [PMID: 9330024]

58. Bromet E, Sonnega A, Kessler RC. Risk factors for DSMIII-R posttraumatic stress disorder: findings from the National Comorbidity Survey. Am J Epidemiol. 1998; 147(4):353-61. [PMID: 9508102]

59. Brewin CR, Andrews B, Valentine JD. Meta-analysis of risk factors for posttraumatic stress disorder in traumaexposed adults. J Consult Clin Psychol. 2000;68(5):748-66. [PMID: 11068961]

60. Ozer EJ, Best SR, Lipsey TL, Weiss DS. Predictors of posttraumatic stress disorder and symptoms in adults: A meta-analysis. Psychol Bull. 2003;129(1):52-73. [PMID: 12555794$]$

61. Dikel TN, Engdahl B, Eberly R. PTSD in former prisoners of war: Prewar, wartime, and postwar factors. J Trauma Stress. 2005;18(1):69-77. [PMID: 16281198]

62. Frommberger UH, Stieglitz RD, Nyberg E, Schlickewei W, Kuner E, Berger M. Prediction of posttraumatic stress disorder by immediate reactions to trauma: A prospective study in road traffic accident victims. Eur Arch Psychiatry Clin Neurosci. 1998;248(6):316-21. [PMID: 9928912]

63. Williams WH, Evans JJ, Needham P, Wilson BA. Neurological, cognitive and attributional predictors of posttrau- matic stress symptoms after traumatic brain injury. J Trauma Stress. 2002;15(5):397-400. [PMID: 12392227

64. Harvey AG, Bryant RA. Predictors of acute stress following motor vehicle accidents. J Trauma Stress. 1999;12(3): 519-25. [PMID: 10467559]

65. Brewin CR, Andrews B, Rose S, Kirk M. Acute stress disorder and posttraumatic stress disorder in victims of violent crime. Am J Psychiatry. 1999;156(3):360-66. [PMID: 10080549$]$

66. Koren D, Arnon I, Klein EM. Acute stress response and posttraumatic stress disorder in traffic accident victims: A one-year prospective, follow-up study. Am J Psychiatry. 1999;156(3):367-73. [PMID: 10080550]

67. Koren D, Arnon I, Klein EM. Long term course of chronic posttraumatic stress disorder in traffic accident victims: A three-year prospective follow-up study. J Behav Res Ther. 2001;39(12):1449-58. [PMID: 11758702]

68. Harvey AG, Bryant RA. Two-year prospective evaluation of the relationship between acute stress disorder and posttraumatic stress disorder following mild traumatic brain injury. Am J Psychiatry. 2000;157(4):626-28. [PMID: 10739425]

69. Bryant RA. Early predictors of posttraumatic stress disorder. Biol Psychiatry. 2003;53(9):789-95. [PMID: 12725971]

70. Heinrichs M, Wagner D, Schoch W, Soravia LM, Hellhammer DH, Ehlert U. Predicting posttraumatic stress symptoms from pretraumatic risk factors: A 2-year prospective follow-up study in firefighters. Am J Psychiatry. 2005;162(12):2276-86. [PMID: 16330591]

71. Beckham JC, Roodman AA, Barefoot JC, Haney TL, Helms MJ, Fairbank JA, Hertzberg MA, Kudler HS. Interpersonal and self-reported hostility among combat veterans with and without posttraumatic stress disorder. J Trauma Stress. 1996;9(2):335-42. [PMID: 8731551]

72. Beckham JC, Calhoun PS, Glenn DM, Barefoot JC. Posttraumatic stress disorder, hostility and health in women: A review of current research. Ann Behav Med. 2002; 24(3):219-28. [PMID: 12173679]

73. Butterfield MI, Forneris CA, Feldman ME, Beckham JC. Hostility and functional health status in women veterans with and without posttraumatic stress disorder: A preliminary study. J Trauma Stress. 2000;13(4):735-41. [PMID: 11109243$]$

74. Frueh BC, Henning KR, Pellegrin KL, Chobot K. Relationship between scores on anger measures and PTSD symptomatology, employment, and compensation-seeking status in combat veterans. J Clin Psychol. 1997;53(8):871-78. [PMID: 9403390]

75. Novaco RW, Chemtob CM. Anger and combat-related posttraumatic stress disorder. J Trauma Stress. 2002;15(2): 123-32. [PMID: 12013063] 
76. Benight CC, Harper ML. Coping self-efficacy perceptions as a mediator between acute stress response and long-term distress following natural disasters. J Trauma Stress. 2002; 15(3):177-86. [PMID: 12092909]

77. Saigh PA, Mroueh M, Zimmerman BJ, Fairbank JA. Selfefficacy expectations among traumatized adolescents. Behav Res Ther. 1995;33(6):701-4. [PMID: 7651463$]$

78. Bryant RA, Guthrie RM. Maladaptive appraisals as a risk factor for posttraumatic stress: A study of trainee firefighters. Psychol Sci. 2005;16(10):749-52. [PMID: 16181434]

79. Schnyder U, Moergeli H, Klaghofer R, Buddeberg C. Incidence and prediction of posttraumatic stress disorder symptoms in severely injured accident victims. Am J Psychiatry. 2001;158(4):594-99. [PMID: 11282694]

80. Dougall AL, Ursano RJ, Posluszny DM, Fullerton CS, Baum A. Predictors of posttraumatic stress among victims of motor vehicle accidents. Psychosom Med. 2001;63(6): 402-11. [PMID: 11382267]

81. Bernat JA, Ronfeldt HM, Calhoun KS, Arias I. Prevalence of traumatic events and peritraumatic predictors of posttraumatic stress symptoms in a nonclinical sample of college students. J Trauma Stress. 1998;11(4):645-64. [PMID: 9870219$]$

82. Resnick HS, Yehuda R, Pitman RK, Foy DW. Effect of previous trauma on acute plasma cortisol level following rape. Am J Psychiatry. 1995;152(11):1675-77. [PMID: 7485635]

83. Davidson JR, Stein DJ, Shalev AY, Yehuda R. Posttraumatic stress disorder: Acquisition, recognition, course and treatment. J Neuropsychiatry Clin Neurosci. 2004;16(2): 135-47. [PMID: 15260364$]$

84. Breslau N. The epidemiology of posttraumatic stress disorder: What is the extent of the problem? J Clin Psychiatry. 2001;62 Suppl 17:16-22. [PMID: 11495091]

85. Seedat S, Stein DJ, Carey PD. Post-traumatic stress disorder in women: Epidemiological and treatment issues. CNS Drugs. 2005;19(5):411-27. [PMID: 15907152]

86. Breslau N, Davis GC, Andreski P, Peterson EL, Schultz LR. Sex differences in posttraumatic stress disorder. Arch Gen Psychiatry. 1997;54(11):1044-48. [PMID: 9366662]

87. Bruns J Jr, Hauser WA. The epidemiology of traumatic brain injury: A review. Epilepsia. 2003;44 Suppl 10:2-10. [PMID: 14511388]

88. Simon RI. Chronic posttraumatic stress disorder: a review and checklist of factors influencing prognosis. Harv Rev Psychiatry 1999;6(6):304-12. [PMID: 10370437$]$

89. Perkonigg A, Pfister H, Stein MB, Hofler M, Lieb R, Maercker A, Wittchen HU. Longitudinal course of posttraumatic stress disorder and posttraumatic stress disorder symptoms in a community sample of adolescents and young adults. Am J Psychiatry. 2005;162(7):1320-27. [PMID: 15994715$]$
90. Bremner JD, Southwick SM, Darnell A, Charney DS. Chronic PTSD in Vietnam combat veterans: Course of illness and substance abuse. Am J Psychiatry. 1996;153(3): 369-75. [PMID: 8610824]

91. Zlotnick C, Warshaw M, Shea MT, Allsworth J, Pearlstein $\mathrm{T}$, Keller MB. Chronicity in posttraumatic stress disorder (PTSD) and predictors of course of comorbid PTSD in patients with anxiety disorders. J Trauma Stress. 1999; 12(1):89-100. [PMID: 10027144]

92. Zlotnick C, Rodriguez BF, Weisberg RB, Bruce SE, Spencer MA, Culpepper L, Keller MB. Chronicity in posttraumatic stress disorder and predictors of the course of posttraumatic stress disorder among primary care patients. J Nerv Ment Dis. 2004;192(2):153-59. [PMID: 14770060]

93. McFarlane AC. Posttraumatic stress disorder: A model of the longitudinal course and the role of risk factors. J Clin Psychiatry. 2000;61 Suppl 15:15-23. [PMID: 10761675]

94. North CS, Kawasaki A, Spitznagel EL, Hong BA. The course of PTSD, major depression, substance abuse, and somatization after a natural disaster. J Nerv Ment Dis. 2004;192(12):823-29. [PMID: 15583503]

95. Solomon Z, Mikulincer M. Trajectories of PTSD: A 20-year longitudinal study. Am J Psychiatry. 2006;163(4):659-66. [PMID: 16585441]

96. Wolfe J, Erickson DJ, Sharkansky EJ, King DW, King LA. Course and predictors of posttraumatic stress disorder among Gulf War veterans: A prospective analysis. J Consult Clin Psychol. 1999;67(4):520-28. [PMID: 10450622]

97. Malt UF, Olafsen OM. Psychological appraisal and emotional response to physical injury: A clinical, phenomenological study of 109 adults. Psychiatr Med. 1992;10(3): 117-34. [PMID: 1410539]

98. North CS, Pfefferbaum B, Tivis L, Kawasaki A, Reddy C, Spitznagel EL. The course of posttraumatic stress disorder in a follow-up study of survivors of the Oklahoma City bombing. Ann Clin Psychiatry. 2004;16(4):209-15. [PMID: 15702569]

99. Schell TL, Marshall GN, Jaycox LH. All symptoms are not created equal: The prominent role of hyperarousal in the natural course of posttraumatic psychological distress. J Abnorm Psychol. 2004;113(2):189-97. [PMID: 15122939]

100. American Psychiatric Association. DSM-III: Diagnostic and Statistical Manual of Mental Disorders. Washington (DC): American Psychiatric Association; 1980.

101. Gray MJ, Bolton EE, Litz BT. A longitudinal analysis of PTSD symptom course: Delayed onset PTSD in Somalia peacekeepers. J Consult Clin Psychol. 2004;72(5):909-13. [PMID: 15482050]

102. Hoge CW, Castro CA, Messer SC, McGurck D, Cotting DI, Koffman RL. Combat duty in Iraq and Afghanistan, 
mental health problems, and barriers to care. $\mathrm{N}$ Engl J Med. 2004;351(1):13-22. [PMID: 15229303]

103. Hoge CW, Auchterlonie JL, Milliken CS. Mental health problems, use of mental health services, and attrition from military service after returning from deployment of Iraq and Afghanistan. JAMA. 2006;295(9):1023-32.

[PMID: 16507803]

104. Ruzich MJ, Looi JC, Robertson MD. Delayed onset of posttraumatic stress disorder among male combat veterans: A case series. Am J Geriatr Psychiatry. 2005;13(5): 424-27. [PMID: 15879593]

105. Prigerson HG, Maciejewski PK, Rosenheck RA. Combat trauma: Trauma with highest risk of delayed onset and unresolved posttraumatic stress disorder symptoms, unemployment and abuse among men. J Nerv Ment Dis. 2001;189(2):99-108. [PMID: 11225693]

106. Dirkzwager AJ, Bramsen I, Van der Ploeg HM. The longitudinal course of posttraumatic stress disorder symptoms among aging military veterans. J Nerv Ment Dis. 2001; 189(12):846-53. [PMID: 11794578]

107. Koenen KC, Stellman JM, Stellman SD, Sommer JF Jr. Risk factors for course of posttraumatic stress disorder among Vietnam veterans: A 14-year follow-up of American Legionnaires. J Consult Clin Psychol. 2003;71(6): 980-86. [PMID: 14622073]

108. Johnson DR, Fontana A, Lubin H, Corn B, Rosenheck R. Long-term course of treatment-seeking Vietnam veterans with posttraumatic stress disorder: Mortality, clinical condition, and life satisfaction. J Nerv Ment Dis. 2004:192(1): 35-41. [PMID: 14718774]

109. Orcutt HK, Erickson DJ, Wolfe J. The course of PTSD symptoms among Gulf War veterans: A growth mixture modeling approach. J Trauma Stress. 2004;17(3):195-202. [PMID: 15253091]

110. Mather FJ, Tate RL, Hannan TJ. Post-traumatic stress disorder in children following road traffic accidents: A comparison of those with and without mild traumatic brain injury. Brain Inj. 2003;17(12):1077-87. [PMID: 14555366]

111. Bryant RA, Marosszeky JE, Crooks J, Baguley IJ, Gurka JA. Posttraumatic stress disorder and psychosocial functioning after severe traumatic brain injury. J Nerv Ment Dis. 2001;189(2):109-13. [PMID: 11225683]

112. King NS. Perseveration of traumatic re-experiencing in PTSD: A cautionary note regarding exposure based psychological treatments for PTSD when head injury and dysexecutive impairment are also present. Brain Inj. 2002; 16(1):65-74. [PMID: 11796100]

113. Yehuda R, Schmeidler J, Giller EL Jr, Siever LJ, BinderByrnes K. Relationship between posttraumatic stress disorder characteristics of Holocaust survivors and their adult offspring. Am J Psychiatry. 1998;155(6):841-43. [PMID: 9619162]
114. Yehuda R, Halligan SL, Grossman R. Childhood trauma and risk for PTSD: Relationship to intergenerational effects of trauma, parental PTSD, and cortisol excretion. Dev Psychopathol. 2001;13(3):733-53. [PMID: 11523857]

115. Seedat S, Niehaus DJ, Stein DJ. The role of genes and family in trauma exposure and posttraumatic stress disorder. Moleular Psychiatry. 2001;6(4):360-62. [PMID: 11443517]

116. True WR, Rice J, Eisen SA, Heath AC, Goldberg J, Lyons MJ, Nowak J. A twin study of genetic and environmental contributions to liability for posttraumatic stress symptoms. Arch Gen Psychiatry. 1993;50(4):257-64. [PMID: 8466386]

117. Segman RH, Shalev AY. Genetics of posttraumatic stress disorder. CNS Spectr. 2003;8(9):693-98. [PMID: 15079143]

118. Radant A, Tsuang D, Peskind ER, McFall M, Raskind W. Biological markers and diagnostic accuracy in the genetics of posttraumatic stress disorder. Psychiatry Res. 2001; 102(3):203-15. [PMID: 11440771]

119. Seckl JR, Meaney MJ. Glucocorticoid "programming” and PTSD risk. Ann N Y Acad Sci. 2006;1071:351-78. [PMID: 16891583]

120. Jordan BD, Relkin NR, Ravdin LD, Jacobs AR, Bennett A, Gandy S. Apolipoprotein E epsilon4 associated with chronic traumatic brain injury in boxing. JAMA. 1997; 278(2):136-40. [PMID: 9214529]

121. Teasdale GM, Murray GD, Nicoll JA. The association between APOE epsilon4, age and outcome after head injury: A prospective cohort study. Brain. 2005;128(Pt 11): 2556-61. [PMID: 16033781]

122. Millar K, Nicoll JA, Thornhill S, Murray GD, Teasdale GM. Long term neuropsychological outcome after head injury: Relation to APOE genotype. J Neurol Neurosurg Psychiatry. 2003;74(8):1047-52. [PMID: 12876232]

123. Pitman RK, Shin LM, Rauch SL. Investigating the pathogenesis of posttraumatic stress disorder with neuroimaging. J Clin Psychiatry. 2001;62 Suppl 17:47-54. [PMID: 11495097$]$

124. Bremner JD, Randall P, Scott TM, Bronen RA, Seibyl JP, Southwick SM, Delaney RC, McCarthy G, Charney DS, Innis RB. MRI-based measurement of hippocampal volume in patients with combat-related posttraumatic stress disorder. Am J Psychiatry. 152(7):973-81. [PMID: 7793467]

125. Elzinga BM, Bremner JD. Are neural substrates of memory the final common pathway in posttraumatic stress disorder (PTSD)? J Affect Disord. 2002;70(1):1-17. [PMID: 12113915]

126. Bremner JD, Staib LH, Kaloupek D, Southwick SM, Soufer R, Charney DS. Neural correlates of exposure to traumatic pictures and sound in Vietnam combat veterans with and without posttraumatic stress disorder: A positron 
emission tomography study. Biol Psychiatry. 1999;45(7): 806-16. [PMID: 10202567]

127. Lanius RA, Williamson PC, Densmore M, Boksman K, Gupta MA, Neufeld RW, Gati JS, Menon RS. Neuronal correlates of traumatic memories in posttraumatic stress disorder: A functional MRI investigation. Am J Psychiatry. 2001;158(11):1920-22. [PMID: 11691703]

128. Nutt DJ, Malizia AL. Structural and functional brain changes in posttraumatic stress disorder. J Clin Psychiatry. 2004;65 Suppl 1:11-17. [PMID: 14728092]

129. Fuchs E, Flugge G, Czeh B. Remodeling of neuronal networks by stress. Front Biosci. 2006;11:2746-58. [PMID: 16720347]

130. Czeh B, Simon M, Schmetting B, Hiemke C, Fuchs E. Astroglial plasticity in the hippocampus is affected by chronic psychosocial stress and concomitant fluoxetine treatment. Neuropsychopharmalogy. 2005;31(8):1616-26. [PMID: 16395301]

131. Sousa N, Lukoyanov NV, Madiera MD, Almeida OF, Paula-Barbarosa MM. Reorganization of the morphology of hippocampal neurites and synapses after stress-induced damage correlates with behavioral improvement. Neuroscience. 2000;97(2):253-66. [PMID: 10799757]

132. Holbourn. Mechanics of head injuries. Lancet. 1943;2: 438-41.

133. Phillips LL, Reeves TM. Interactive pathology following traumatic brain injury modifies hippocampal plasticity. 2001;19(3-4):213-35. [PMID: 12082223]

134. Yehuda R. Biology of posttraumatic stress disorder. J Clin Psychiatry. 2001;62 Suppl 17:41-46. [PMID: 11495096]

135. Yehuda R. Biology of posttraumatic stress disorder. J Clin Psychiatry. 2000;61 Suppl 7:14-21. [PMID: 10795605]

136. Aimaretti G, Ambrosio MR, Di Somma C, Fusco A, Cannavo S, Gasperi M, Scaroni C, De Marinis L, Benvenga S, degli Uberti EC, Lombardi G, Mantero F, Martino E, Giordano G, Ghigo E. Traumatic brain injury and subarachnoid haemorrhage are conditions at high risk for hypopituitraism: Screening study at 3 months after the brain injury. Clin Endocrinol (Oxf). 2004:61(3):320-26.

[PMID: 15355447]

137. Benvenga S, Campenni A, Ruggeri RM, Trimarchi F. Clinical review 113: Hypopituitarism secondary to head trauma. J Clin Endocrinol Metab. 2000;85(4):1353-61. [PMID: 10770165]

138. Pearlstein T. Antidepressant treatment of posttraumatic stress disorder. J Clin Psychiatry. 2000;61 Suppl 7:40-43. [PMID: 10795608]

139. Hageman I, Andersen HS, Jorgensen MB. Post-traumatic stress disorder: A review of psychobiology and pharmacotherapy. Acta Psychiatr Scand. 2001;104(6):411-22.

[PMID: 11782234]
140. Friedman MJ. What might the psychobiology of posttraumatic stress disorder teach us about future approaches to pharmacotherapy? J Clin Psychiatry. 2000;61 Suppl 7: 44-51. [PMID: 10795609]

141. Schmidt RH, Grady MS. Loss of forebrain cholinergic neurons following fluid-percussion injury: Implications for cognitive impairment in closed head injury. J Neurosurg. 1995;83(3):496-502. [PMID: 7666229]

142. Arciniegas DB. The cholinergic hypothesis of cognitive impairment caused by traumatic brain injury. Curr Psychiatry Rep. 2003;5(5):391-99. [PMID: 13678561]

143. Arciniegas DB, Topkoff JL. Applications of the P50 evoked response to the evaluation of cognitive impairments after traumatic brain injury. Phys Med Rehabil Clin N Am. 2004;15(1):177-203. [PMID: 15029905$]$

144. Karakucek EI, Pasaoglu H, Pasaoglu A, Oktem S. Endogenous neuropeptides in patients with acute traumatic head injury. II: Changes in the levels of cerebrospinal fluid substance P, serotonin and lipid peroxidation products in patients with head trauma. Neuropeptides. 1997;31(3): 259-63. [PMID: 9243523]

145. Lipsky RH, Sparling MB, Ryan LM, Xu K, Salazar AM, Goldman D, Warden DL. Association of COMT Val158Met genotype with executive functioning following traumatic brain injury. J Neuropsychiatry Clin Neurosci. 2005;17(4):465-71. [PMID: 16387984]

146. Miller LP, Lyeth BG, Jenkins LW, Oleniak L, Panchision D, Hamm RJ, Phillips LL, Dixon CE, Clifton GL, Hayes RL. Excitatory amino acid receptor subtype binding following traumatic brain injury. Brain Res. 1990;526(1): 103-7. [PMID: 1964103]

147. Brady KT, Killeen TK, Brewerton T, Lucerini S. Comorbidity of psychiatric disorders and posttraumatic stress disorder. J Clin Psychiatry. 2000;61 Suppl 7:22-32. [PMID: 10795606]

148. Kessler RC, McGonagle KA, Zhao S, Nelson CB, Hughes M, Eshleman S, Wittchen HU, Kendler KS. Lifetime and 12-month prevalence of DSM-III-R psychiatric disorders in the United States: Results from the National Comorbidity Survey. Arch Gen Psychiatry. 1994;51(1):8-19. [PMID: 8279933]

149. Shalev AY. What is posttraumatic stress disorder? J Clin Psychiatry. 2001;62 Suppl 17:4-10. [PMID: 11495095$]$

150. Chilcoat HD, Breslau N. Posttraumatic stress disorder and drug disorders: Testing causal pathways. Arch Gen Psychiatry. 1998;55(10):913-17. [PMID: 9783562$]$

151. Briere J, Scott C, Weathers F. Peritraumatic and persistent dissociation in the presumed etiology of PTSD. Am J Psychiatry. 2005;162(12):2295-2301. [PMID: 16330593]

152. Ursano RJ, Bell C, Eth S, Friedman M, Norwood A, Pfefferbaum B, Pynoos JD, Zatzick DF, Benedek DM, McIntyre JS, Charles SC, Altshuler K, Cook I, Cross CD, Mellman L, 
Moench LA, Norquist G, Twemlow SW, Woods S, Yager J; Work Group on ASD and PTSD; Steering Committee on Practice Guidelines. Practice guideline for the treatment of patients with acute stress disorder and posttraumatic stress disorder. Am J Psychiatry. 2004;161 Suppl 11:3-31. [PMID: 15617511]

153. Huppert JD, Moser JS, Gershuny BS, Riggs DS, Spokas M, Filip J, Hajcak G, Parker HA, Baer L, Foa EB. The relationship between obsessive-compulsive and posttraumatic stress symptoms in clinical and nonclinical samples. J Anxiety Disord. 2005;19(1):127-36. [PMID: 15488372]

154. Kessler RC, Borges G, Walters EE. Prevalence and risk factors for lifetime suicide attempts in the National Comorbidity Study. Arch Gen Psychiatry. 1999;56(7): 617-26. [PMID: 10401507]

155. Bryant RA, Moulds M, Guthrie R, Nixon RD. Treating acute stress disorder following mild traumatic brain injury. Am J Psychiatry. 2003;160(3):585-87. [PMID: 12611847$]$

156. Bleiberg J, Ciulla R, Katz BL. Psychological components of rehabilitation programs for brain-injured and spinalcord-injured patients. In: Sweet JJ, Rozensky RH, Tovian SS, editors. Handbook of clinical psychology in medical settings. New York (NY): Plenum Press; 1991. p. 375-400.

157. Williams WH, Evans JJ, Wilson BA. Neurorehabilitation for two cases of post-traumatic stress disorder following traumatic brain injury. Cognit Neuropsychiatry. 2003; 8(1):1-18. [PMID: 16571547]

158. Post Traumatic Stress Disorder: VA/DoD Clinical Practice Guidelines [homepage on the Internet]. Washington (DC): Department of Veterans Affairs, Office of Quality and Performance; c2006 [cited Jun 2006] Available from: http://www.oqp.med.va.gov/cpg/PTSD/PTSD Base.htm

159. Veterans Health Initiative [homepage on the Internet]. Washington (DC): Department of Veterans Affairs, VHA Office of Public Health and Environmental Hazards; c2007 [updated 2007 Jan 17; cited Jun 2006]. Available from: http://www1.va.gov/vhi

160. Boehnlein JK, Kinzie JD. Pharmacologic reduction of CNS noradrenergic activity in PTSD: The case for clonidine and prazosin. J Psychiatr Pract. 2007;13(2):72-78. [PMID: 17414682$]$

161. Raskind MA, Peskind ER, Hoff DJ, Hart KL, Holmes HA, Warren D, Shofer J, O’Connell J, Taylor F, Gross C, Rohde $\mathrm{K}$, McFall ME. A parallel group placebo controlled study of prazosin for trauma nightmares and sleep disturbance in combat veterans with post-traumatic stress disorder. Biol Psychiatry. 2007;61(8):928-34. [PMID: 17069768]

162. Black DW. Efficacy of combined pharmacotherapy and psychotherapy versus monotherapy in the treatment of anxiety disorders. CNS Spectr. 2006;11(10 Suppl 12):29-33. [PMID: 17008828]
163. Cahill SP, Foa EB, Hembree EA, Marshall RD, Nacash N. Dissemination of exposure therapy in the treatment of posttraumatic stress disorder. J Trauma Stress. 2006;19(5): 597-610. [PMID: 17075914]

164. Davis JL, Wright DC. Randomized clinical trial for treatment of chronic nightmares in trauma-exposed adults. J Trauma Stress. 2007;20(2):123-33. [PMID: 17427914]

165. Rabe S, Dorfel D, Zollner T, Maercker A, Karl A. Cardiovascular correlates of motor vehicle accident related posttraumatic stress disorder and its successful treatment. Appl Psychophysiol Biofeedback. 2006;31(4):315-30. [PMID: 17094031$]$

166. Devilly GJ. Power Therapies and possible threats to the science of psychology and psychiatry. Aust N Z J Psychiatry. 2005;39(6):437-45. [PMID: 15943644]

167. Davidson PR, Parker KC. Eye movement desensitization and reprocessing (EMDR): A meta-analysis. J Consult Clin Psychol. 2001;69(2):305-16. [PMID: 11393607]

168. Shepherd J, Stein K, Milne R. Eye movement desensitization and reprocessing in the treatment of post-traumatic stress disorder: A review of an emerging therapy. Psychol Med. 2000;30(4):863-71. [PMID: 11037095]

169. Elofsson UO, von Scheele B, Theorell T, Sondergaard HP. Physiological correlates of eye movement desensitization and reprocessing. J Anxiety Disord. Epub 2007 Jun 3. [PMID: 17604948$]$

170. Bisson JI, Ehlers A, Matthews R, Pilling S, Richards D, Turner S. Psychological treatments for chronic posttraumatic stress disorder. Systematic review and meta-analysis. Br J Psychiatry. 2007;190:97-104. [PMID: 17267924]

171. Seidler GH, Wagner FE. Comparing the efficacy of EMDR and trauma-focused cognitive-behavioral therapy in the treatment of PTSD: A meta-analytic study. Psychol Med. 2006;36(11):1515-22. [PMID: 16740177]

172. Van der Kolk BA, Spinazzola J, Blaustein ME, Hopper JW, Hopper EK, Korn DL, Simpson WB. A randomized clinical trial of eye movement desensitization and reprocessing (EMDR), fluoxetine and pill placebo in the treatment of posttraumatic stress disorder: Treatment effects and longterm maintenance. J Clin Psychiatry. 2007;68(1):37-46. [PMID: 17284128]

173. Charney DS. Psychobiological mechanisms of resilience and vulnerability: Implications for successful adaptation to extreme stress. Am J Psychiatry. 2004;161(2):195-216. [PMID: 14754765]

Submitted for publication December 20, 2006. Accepted in revised form August 23, 2007. 